\title{
Determiners in bilingual German-Italian children: What they tell us about the relation between language influence and language dominance*
}

TANJA KUPISCH

Hamburg University/Kiel University

\begin{abstract}
This study addresses the question of whether language dominance and cross-linguistic influence are related by investigating the acquisition of determiner omission in four bilingual German-Italian children. The study begins by showing that monolingual Italian learners omit determiners less extensively than monolingual German learners. If bilingual children had two autonomous grammatical systems, this contrast should be mirrored in their language acquisition. The analysis suggests the contrary. The bilingual children are compared in terms of language balance and language influence in determiner use. Based on the analysis, I argue that influence is not dependent on language dominance alone. Rather, both language dominance and the properties of the target languages must be taken into account when predicting cross-linguistic influence.
\end{abstract}

\section{Introduction}

Traditionally, there have been two contrary views in research on children acquiring two languages simultaneously. Some researchers believed and some still believe that the bilingual child begins the acquisition process with one language system that combines elements of his/her two languages (e.g. Swain, 1972; Leopold, 1978; Volterra and Taeschner, 1978; Vihman, 1985). This position has become known as the SINGLE SYSTEM HYPOTHESIS Or UNITARY LANGUAGE SYSTEM HYPOTHESIS. Later, especially from the late 1980s, researchers have provided cumulative evidence for the AUTONOMY HYPOTHESIS, claiming that bilingual children separate their languages from early on (e.g. Lindholm and Padilla, 1978; Meisel, 1986, 1989; Genesee, 1989; De Houwer, 1990; see also the publications in Meisel, 1990, 1994). Today, the autonomy hypothesis is widely accepted and may be considered the dominant view in research on bilingualism.

\footnotetext{
* Most of the research presented in this paper was funded by the German Science Foundation (DFG). I am very grateful to Gisela Szagun and the authors of the Tonelli and Calambrone corpora for making their data available at CHILDES. In addition, I would like to thank the following people for their insightful comments on an earlier version of this paper or on the thesis on which it is based: three anonymous reviewers, Petra Bernardini, Jonas Granfeldt, Conxita Lleó, Jürgen Meisel, Natascha Müller, Suzanne Schlyter, and Frank Zenker. All remaining errors are mine.
}

Address for correspondence

Winterhuder Marktplatz 18, D-22299 Hamburg, Germany

E-mail: tanja-kupisch@gmx.de
Despite the assumption of differentiated linguistic systems in bilingual development, many researchers do not deny that the languages are in contact and may influence each other. The most apparent evidence of interaction is the occurrence of mixed utterances, i.e. utterances containing elements from both languages. According to Paradis and Genesee (1996), however, mixing merely reflects an "on-line" interaction between the two languages in performance. The authors distinguish mixing from SYSTEMIC INFLUENCE at the level of competence, which is sustained over a period of time and causes differences in a bilingual's rate of development in comparison with a monolingual's. They speak of ACCELERATION when a grammatical property emerges in the grammar EARLIER than would be usual in monolingual acquisition. A grammatical property emerging in the grammar LATER than would be usual in monolingual acquisition is referred to as DELAY. The present article is concerned with language influence in the acquisition of syntax, more precisely, in the acquisition of nominal determiners. In particular, I will address the question of whether influence is driven by an imbalance in the child's development of the two languages (i.e. LANGUAGE DOMINANCE) or by properties inherent to the target languages.

In research on bilingual first language acquisition, both mixing and systemic influence have been related to the situation in which one language of the child is dominant. For example, Petersen (1988, p. 486) formulated the DOMINANT LANGUAGE HYPOTHESIS, according to which grammatical morphemes of the dominant language may co-occur with lexical morphemes of either the dominant 
or the non-dominant language, while grammatical morphemes of the non-dominant language may cooccur only with lexical morphemes of the non-dominant language. While stressing that mixing and language separation are not mutually exclusive, Genesee (1989, p. 166) proposed that "if the differentiated-language systems hypothesis were true, one would expect to find more frequent use of items from the weaker language in contexts where that language is being used than in contexts where the stronger language is being used, even though items from the stronger language might predominate in both contexts". His assumptions are in line with Petersen's, implying that mixing occurs more frequently in the weaker language. Genesee, Nicoladis and Paradis (1995) investigated mixing and dominance in French-English bilingual children and found that the children tended to mix more when using their nondominant language than when using their dominant language. Bernardini and Schlyter (2004) proposed the IVY-HYPOTHESIS, according to which, during interaction in the weaker language, bilingual children use syntactic structures of the stronger language. Grosjean (1982, p. 190) even noted that "dominance retards [language] differentiation by imposing aspects of the dominant language on the weaker one".

Recent work indicates that language influence in the form of lexical or syntactic borrowing no longer bears the negative image of a linguistic deficit. Rather, it is seen as a strategy employed by children to express something for which they do not yet have the linguistic means. According to Grosjean (1982, p. 191), resorting to the stronger language may help bilingual children to avoid breakdowns in communication. Where monolingual children employ strategies such as overextension (e.g. they may use the word $d o g$ to refer to dogs, lambs, cats, wolves), or the insertion of syntactic placeholders, i.e. phonologically reduced and morphologically undetermined function words (Bottari, Cipriani and Chilosi, 1993/94), bilinguals "pull out their resources" (Gawlitzek-Maiwaldt and Tracy, 1996) and borrow lexical elements or syntactic structure from their second first language. However, this strategy may not be motivated by language dominance alone.

Gawlitzek-Maiwaldt and Tracy (1996) stressed that bilingual children may use syntactic structure from one of their languages because it is easier to acquire in this language than in the other. This raises the question whether language dominance can serve as a general explanation for language influence in bilinguals. Hulk and Müller (2000) explicitly argued against this view, claiming that influence is driven by factors internal to the language systems themselves. However, their claims were based on data of fairly balanced children, while most studies arguing the contrary worked with unbalanced children. To test the claim that influence and dominance are causally ${ }^{1}$ related necessitates a systematic comparison of language influence in balanced and unbalanced children. The latter constitutes the empirical goal of the present study, which examines children differing in terms of language balance.

The paper begins with a comparison of determination and articles in German and Italian, arguing that Italian is more beneficial to their acquisition. Subsequently, an inter-linguistic contrast in the rate of determiner acquisition between monolingual Italian and German children is established, based on previous research and an additional corpus analysis. I then introduce the bilingual children, determine their degree of language balance, and examine the evolution of determiners in the bilingual data with respect to language influence. Three hypotheses for the occurrence of language influence will be tested:

(i) If the language systems of bilingual children are autonomous, then the contrast found in monolingual learners should also appear in bilinguals, because the reasonable assumption is that each system works just by itself, as implied by "autonomous". Should one fail to observe this contrast, then this indicates that the systems are not autonomous.

(ii) If language dominance were the only factor to determine language influence, then a balanced child should not show any effects of language influence. Should it be observed, however, that balanced children also show effects of language influence, then, language dominance cannot be the only factor.

(iii) If language influence were driven by language internal factors, viz., the complexity of a grammatical domain in a language, such that the language providing the less complex analysis for a grammatical domain influences the language with the more complex analysis, the same language should be subject to influence, independently of balance.

The paper ends with a discussion and concludes that the two languages of a bilingual child are in contact and may influence each other, and that influence depends on both language internal factors (i.e. the properties of the grammatical domain in a language) and language external factors (i.e. language dominance).

\section{Articles and determination in German and Italian}

The class of determiners includes articles, demonstratives, pronouns and quantifiers. In this article I will be concerned with prenominal (e.g. that book) rather than pronominal

\footnotetext{
1 In speaking of a CAUSAL RELATION between (i) language dominance and (ii) language influence, I mean to say that the question is whether a value of a measure for (i) may uniquely serve to predict a value of (ii), and not whether there is merely a correlation between the two.
} 
Table 1. Definite articles in German and Italian.

\begin{tabular}{cccccccc}
\hline \hline & & \multicolumn{2}{c}{ German } & & \multicolumn{2}{c}{ Italian } \\
\cline { 3 - 4 } & & M & F & N & M & F \\
\hline SG & NOM & der & die & das & il (lo, l') & la (1') \\
& GEN & des & der & des & & \\
& DAT & dem & der & dem & & \\
PL & ACC & den & die & das & & \\
& NOM & & die & & i (gli) & le \\
& GEN & & der & & & \\
& DAT & & den & & & \\
& ACC & & die & & & \\
\hline \hline
\end{tabular}

$\mathrm{M}=$ masculine; $\mathrm{F}=$ feminine $\quad \mathrm{N}=$ neuter $\quad \mathrm{SG}=$ singular; $\mathrm{PL}=$ plural $; \mathrm{NOM}=$ nominative $; \quad \mathrm{GEN}=$ genitive $; \mathrm{DAT}=$ dative; $\mathrm{ACC}=$ accusative

determiners (e.g. I want that) and I will focus particularly on articles, as they are the most frequent type of prenominal determiner and the type which tends to emerge first in acquisition. ${ }^{2}$ Articles are at the crossroads between phonology, morphology, syntax, semantics, and pragmatics in both German and Italian. The following inter-language comparison of their properties indicates that Italian is more beneficial to article acquisition than German. This leads to the expectation that articles are acquired earlier in Italian, and makes articles an ideal testing ground for the occurrence of language influence in bilingual children acquiring these languages simultaneously.

We may observe that both German (Ge) and Italian (It) have prenominal definite and indefinite articles, both realized as free morphemes. A contrastive overview of article forms in the two languages is provided in Tables 1 and 2, which show that German has one more gender class than Italian, and that German articles additionally encode case distinctions.

The occurrence of the Italian articles $l o, l$ ', gli, uno, $u n$ ' and degli is phonologically conditioned. Uno, lo, gli and $d e g l i$ are used before masculine nouns beginning with a consonant cluster containing [z] or [s], e.g. uno/lo zio "a/the uncle", degli/gli zii "some/the uncles". The forms gli, degli, l' and un' occur before vowel-initial nouns, e.g. degli/gli alberi "some/the trees", un'll'anatra "a/the duck". Definite articles in both languages may form clusters with prepositions, e.g. Ge. auftdem becomes aufm "on the", and Italian su+la becomes sulla "in the". As shown in Table 2, all German indefinite articles, except

2 When dealing with determiner omission in acquisition data, it is at times impossible to determine which type of determiner has been omitted. Therefore, I shall use the more general term DETERMINER OMISSION rather than ARTICLE OMISSION. the genitive forms, have reduced variants, which are very common in spoken language. Furthermore, there is much syncretism in the German article system. As Table 2 indicates, the form der is found in the masculine and in the feminine paradigm, it occurs with three different cases, and it may be either singular or plural. In short, from a morphological point of view, the German article system is more complex than the Italian one, as there are more article-types overall (recall that each form has reduced and contracted variants), each individual type encodes more formal features, and the form-function mapping is opaque.

As far as phonology is concerned, the vocalic endings of most Italian DPs ${ }^{3}$ harmonize with the vowel in the article, e.g. una/la ragazza "a/the girl", delle/le ragazze "some/the girls", dei/i ragazzi "some/the boys", etc. In these cases, the shape of the article is univocally predictable. There are noun classes for which this does not hold, e.g. nouns with the singular ending in -e may be masculine (il cane "the dog") or feminine (la lepre "the hare"), but these constitute the minority. ${ }^{4}$ In German, by contrast, the noun endings do not harmonize with the articles. There is some statistical correlation between the phonological properties of some nouns and their gender (and, hence, the shape of the article; cf. Köpcke, 1982) but, unlike Italian, there is no univocal predictability. If phonological cues are helpful in article acquisition, which is a plausible assumption, Italian is more beneficial to article acquisition than German.

Let us turn to prosody. Prosodically, the Italian article is always proclitic to the noun, while especially the reduced variants of German articles may form a prosodic unit with the preceding word, as shown in (1) (cf. Lleó, 2001).

(1) a. Ge. syntactic unit: Mario hat ['n Hund] gesehen. prosodic unit: Mario [hat' n] Hund gesehen. Mario has a dog seen

b. It. syntactic unit: Mario ha visto [un cane]. prosodic unit: Mario ha visto [un cane]. Mario has seen a dog "Mario saw a dog."

3 In this study, I use the term DETERMINER PHRASE (and the abbreviation DP) as a theoretically-neutral term of what has traditionally been referred to as NP and since Abney's (1987) proposal of the DPhypothesis is commonly referred to as DP.

4 According to Chini (1995), the noun classes with a singular ending in $-o$ or $-a$, for which the gender is totally predictable, constitute $71.5 \%$ (type-frequency) of all Italian nouns. Kupisch, Müller and Cantone (2002) indicated a token-frequency of $88 \%$ for these noun classes in child-directed adult speech. Note that the predictability of gender does not imply that the article RHYMES with the noun ending (the masculine singular article $i l$ constitutes an exception here, e.g. il ragazzo). Nonetheless, the strong correlation between $i l$ and - $o$ may help the child in determining the shape of the article, and indirectly, promote article acquisition. 
Table 2. Indefinite articles in German and Italian.

\begin{tabular}{|c|c|c|c|c|c|c|}
\hline & & \multicolumn{2}{|c|}{ German } & \multirow[b]{2}{*}{$\mathrm{N}$} & \multicolumn{2}{|c|}{ Italian } \\
\hline & & $\mathrm{M}$ & $\mathrm{F}$ & & M & $\mathrm{F}$ \\
\hline \multirow[t]{4}{*}{ SG } & NOM & ein/'n & eine/'ne & ein/'n & un (uno) & una (un') \\
\hline & GEN & eines & einer & eines & & \\
\hline & DAT & einem/'nem & einem/'nem & einem/'nem & & \\
\hline & $\mathrm{ACC}$ & einen/'nen/'n & eine/'ne & ein/'n $n$ & & \\
\hline PL & & & $\varnothing$ & & dei (degli) / Ø & delle / Ø \\
\hline
\end{tabular}

The examples illustrate that syntactic units and prosodic units go hand in hand in Italian, while there may be mismatches between syntax and prosody in German. If prosodic factors play a role in acquisition, it is likely that they facilitate article acquisition in Italian but render the acquisition of German articles more difficult.

If we look at article use in obligatory contexts, we may observe many parallels between the two languages. In both German and Italian, determination is obligatory with singular count nouns in argument position.

(2) a. Ge. *Katze sieht Maus. vs. Die/Eine Katze sieht die/eine Maus.

b. It. *Gatto vede topo. vs. Il/un gatto vede il/un topo.

"Cat sees mouse." "The/a cat sees the/a mouse."

An article (or another determiner) is also required with plural and mass nouns if they have a specific reading, as in $(3) .^{5}$

(3) a. Ge. Hast du die Tomaten und den Käse besorgt? (specific)

b. It. Hai comprato i pomodori e il formaggio? (specific)

"Did you buy the tomatoes and the cheese?"

With non-specific (non-generic) DPs, on the other hand, Italian makes optional use of partitive articles (del, della etc.) and indefinite plural articles (dei, delle, etc.), but we find zero-determination in German, which has no corresponding articles.

(4) a. Ge. Hast du Tomaten und Käse besorgt?

b. It. Hai comprato (dei) pomodori e (del) (non-specific) formaggio? "Did you buy tomatoes and cheese?" (non-specific)

With generic DPs where the noun is plural or mass, Italian requires an article, while the article in the equivalent

5 Here, a DP is understood to be specific if it refers to a particular individual, and non-specific if it does not refer to a specific individual.
German sentence must be absent. The use of an article in the German example (5a) would not render the sentence ungrammatical but it would attribute a specific reading to it.

(5) a. Ge. Katzen fressen Mäuse.

b. It. *Gatti mangiano topi. vs. "Cats eat mice."

I gatti mangiano i topi.

"The cats eat the mice."

Another difference is found in the use of articles with possessive DPs. In Italian, the possessive pronoun has the status of an adjective (cf. Giorgi and Longobardi, 1991; Lyons 1999) and must be combined with an article, e.g. il mio gatto "my cat". Kinship terms constitute an exception, e.g. mio fratello "my brother". In German, where the possessive has the status of a definite determiner, article and possessive pronoun are in complementary distribution. The contrast is indicated in (6a) vs. (6b).

(6) a. Ge. meine Katze vs. *die meine Katze

b. It. *mio gattto vs. il mio gatto my cat the my cat

Furthermore, where Italian makes use of the definite article with inalienable possessive constructions, articles must be absent in German if the noun is in the plural.
(7) a. Ge. Mario hat blaue Augen. vs. *Mario hat die blauen Augen.
b. It. *Mario ha occhi blu. vs. Mario ha gli occhi blu. "Mario has blue eyes."

In some Northern Italian dialects, the definite article is also used before proper names, e.g. Ho visto la Maria "I saw (the) Mary". Proper names in Standard German are used without articles, but most speakers do not consider such combinations to be ungrammatical.

Examples (3)-(5a) and (3)-(4b) represent DPs in which the presence/absence of an article has no consequences for their grammaticality but for their semantic interpretation. These examples show that article use is at the interface between syntax and semantics. Hence, one may conjecture 
two opposite hypotheses, one being that Italian is more beneficial to acquisition because it requires articles regardless of the semantic interpretation of the DP, the other being that German is more beneficial to article acquisition as semantic meaning is visibly mapped onto syntax (bare nouns being non-specific and article+noun sequences being specific). Both hypotheses have shortcomings, however. It is true that German shows some correlation between syntactic representation and semantic interpretation, as German bare nouns tend to be non-specific and German article-noun sequences tend to be specific, while the prenominal position in Italian tends to be filled regardless of specificity. However, these are just TENDENCIES. In fact, bare nouns constitute $11 \%$ in the Italian (adult) input to the child. Contexts include plural, mass abstract object nouns, complements of prepositions, predicative nouns, and others (Kupisch, 2004). That is, zero determination is not entirely absent in Italian and, vice versa, there are non-specific German DPs with articles, e.g. Ich gehe eine Pizza kaufen "I'm gonna buy a pizza", Die Katze ist ein Säugetier "The cat is a mammal". From these observations I conclude that Italian and German are equally complex in terms of the syntax/semantics interface. It should be emphasized, however, that the overall number of bare nouns is higher in German (18\%) than in Italian (11\%) (see Kupisch, 2004). It is conceivable that the higher token-frequency of nouns with articles in Italian increases the child's awareness of the article at an earlier age in this language.

Finally, article use is also dependent on pragmatic factors. This has no bearing on the question of whether an article should be used or not, but rather on the question of which article form is appropriate. To give an example, the use of a definite article as opposed to an indefinite article in (8) depends on whether the addressee of the utterance can be presumed to be familiar with the referent, or capable of identifying it. The difference in meaning becomes clear in (9a), follow-up sentences to (8a), with indefinite articles, and in (9b), follow-up sentences to (8b), with definite articles.

(8) Ge. Heute morgen habe ich a) einen
It. Stamattina ho visto
b) den Fuchs gesehen.
a) una
b) la volpe.

"This morning I saw a/the fox."

(9) a. Ge. Füchse sind selten in dieser Region.

It. Le volpi sono rare in questa parte del paese. "Foxes are rare in this part of the country."

b. Ge. Erinnerst du dich? Letzte Woche haben wir ihn auch schon gesehen.

It. Ti ricordi? L'abbiamo già vista la settimana scorsa.

"Do you remember? We already saw it last week."
The examples indicate that the two languages are largely similar in terms of the syntax/pragmatics interface.

Concluding this comparison, we may note that German and Italian show a total overlap at the syntactic level, as both have zero determination and nouns with determiners. There is also a complete overlap in the rules governing the syntax/pragmatics interface. The overlap at the syntax/semantics interface, by contrast, is only partial. Furthermore, the languages differ with respect to the following properties which make German determiners more complex and challenging in acquisition than Italian determiners.

(i) The overall number of different article types is higher in German.

(ii) Each individual article-type in German encodes a higher number of grammatical features (i.e. case in addition to gender and number).

(iii) Noun-final and article-final vowels often harmonize in Italian but not in German.

(iv) There may be mismatches between prosodic units and syntactic DPs in German, while there is a one-toone correspondence between prosody and syntax in Italian.

(v) German displays a lower token-frequency of determiner-noun sequences as opposed to bare nouns than Italian.

It is plausible to assume that the properties (i) and (ii) make the German-learning child "wait-and-see", i.e. make $\mathrm{him} / \mathrm{her}$ omit determiners to avoid the usage of wrong forms. The properties (iii) through (v), on the other hand, may increase the Italian-learning child's awareness of the prenominal position at an earlier age. Based on these observations one may expect articles to be acquired earlier by Italian-learning children than by Germanlearning children, which shall be tested in the following section. A bilingual child acquiring German and Italian simultaneously is exposed to the less beneficial properties of German and to the more beneficial properties of Italian at the same time. The consequences will be elucidated in more detail further below.

\section{The acquisition of determiners in monolingual children}

This section summarizes previous research on determiner acquisition dealing with German and Italian data as well as typologically similar languages, and presents a comparative analysis of longitudinal data from monolingual German and Italian children. 


\section{Previous studies}

Article/determiner omission is a well-documented phenomenon in early child speech. According to Chierchia, Guasti and Gualmini (1999), children pass through three stages: (i) the BARE-NOUN STAGE during which all nouns occur bare, (ii) the VARIATION STAGE in which both bare nouns and nouns with determiners occur, and (iii) the TARGET-STAGE in which nouns are used with determiners whenever required. Utterances such as (10a) are typical of the first or second stage, while utterances, such as (10b) are typical of the second or third stage.

(10) a. qua, falla
there butterfly
$\begin{aligned} & \text { b. guarda la farfalla piccola (Marta 2;6,10) } \\ & \text { look the butterfly small }\end{aligned}$

So far, there is no published work comparing the acquisition of articles or determiners in monolingual German and Italian children, but some insight may be gained by looking at studies treating only one of the two languages or typologically similar languages.

Research on article acquisition in Italian children indicates that the first articles are used at an early age, sometimes even before $1 ; 6$, and never occur later than the age of 2;0. Pizzuto and Caselli (1992, p. 521) study three Italian children and report that the feminine definite article $l a$ occurs at the ages of 1;4 and 1;5, and the masculine definite article $i l$ between $1 ; 7$ and 2;1. Bottari et al. (1993/94, p. 340) observe article-like fillers from the age of $1 ; 8$ onwards. They point out that these first forms are phonologically reduced, taking the form of $[\mathrm{e}],[\partial]$ and [a], and are, thus, morphologically underdetermined. Nevertheless, they clearly have the function of marking the syntactic position. The Italian child Camilla studied by Antelmi (1997) produces her first non-formulaic articles at the age of $1 ; 9$.

German-learning children start to produce articles at a later age than Italian-learning children. Penner and Weissenborn (1996) observe first article-like fillers at the age of 1;10 in their German data. Lleó (2001) examines four German children, and reports that the first articles occur at $1 ; 8$, but that their production only increases very slowly between the ages of $1 ; 10$ and 2;1, which is around half a year later than the Spanish-speaking children she studied. Kupisch (2000) analyzes a monolingual German child longitudinally and observes that the first three determiners (die, den, de "the") occur sporadically from age 2;2 but there are never more than two tokens per recording until age 2;4 (compared to between 50 and 109 bare nouns).

As mentioned before, there is no investigation treating determiner acquisition in both German and Italian, but some researchers have examined similar language combinations. Chierchia et al. (1999) compare French, Italian, and English. Lleó and Demuth (1999) and Lléo (2001) study Spanish and German. Guasti et al.
(2004) investigate Catalan, Italian and Dutch. All studies document that determiners start to be used at earlier ages in the Romance languages and that children acquiring a Romance language omit articles less extensively than children acquiring a Germanic language.

In both German and Italian, children generally cease to omit articles in obligatory contexts before they turn 3;0 (for Italian see Pizzuto and Caselli, 1992; Caselli, Leonard, Volterra and Campagnoli, $1993 ;{ }^{6}$ for German see Penner and Weissenborn, 1996; Eisenbeiss, 2000, 2002). According to Chierchia et al. (1999), children acquiring a Romance language cease to omit articles with a lower MLU (mean length of utterance) than children acquiring a Germanic language. However, MLU-based accounts are to be considered with some caution. Since nouns constitute a large portion of children's early lexicons, the MLU increase is not independent of article use. Put differently, children who use articles more frequently than others also have higher MLUs.

In conclusion, previous work on determiner acquisition suggests that Italian children start producing determiners at an earlier age than German children and show lower rates of determiner-omission in obligatory contexts. However, German and Italian have never been examined in a single study, and for methodological reasons, full comparability cannot be ensured with studies carried out by different research teams. Therefore, the analysis of the bilingual data shall be preceded by a cross-linguistic study with monolingual learners, which is summarized in the next section.

\section{A cross-linguistic study on determiner acquisition in monolingual children}

\section{The monolingual children}

Originally, three longitudinal corpora of each language were used. Since one of the Italian-learning children, Elisa, exhibited exceptionally high MLU-values (above 3 at the first recording at 1;10,4), a fourth corpus of Italian (Martina) was used. The three Italian corpora Elisa, Gregorio and Marco constitute the Tonelli database, and the Martina-corpus forms part of the Calambronedatabase (Cipriani et al., 1989). The two German corpora Falko and Emely were collected by Gisela Szagun (Szagun, 2001). All data are available at the CHILDES database (MacWhinney and Snow, 1985). The German Chantal-corpus was collected and transcribed by Natascha Müller together with the author. An overview of the age span and the number of recordings covered by the analysis is provided in Table 3. To give an idea of the corpus

\footnotetext{
6 The results by Pizzuto and Caselli (1992) and Caselli et al. (1993) differ from the other studies in that their acquisition criterion was not $90 \%$ of suppliance in obligatory contexts, but $90 \%$ of MORPHOLOGICALLY CORRECT SUPPLIANCE in obligatory contexts. Also, the acquisition criterion was defined for each article type separately.
} 
Table 3. Overview of the monolingual corpora.

\begin{tabular}{llllll}
\hline \hline $\begin{array}{l}\text { Monolingual } \\
\text { corpora }\end{array}$ & Language & AGE-span & $\begin{array}{l}\text { Number of } \\
\text { recordings }\end{array}$ & $\begin{array}{l}\text { Total number } \\
\text { of child UTT }\end{array}$ & Origin \\
\hline Falko & German & $1 ; 4-2 ; 5,16$ & 11 & 3715 & Szagun (2001) \\
Emely & & $1 ; 4,7-3 ; 0,7$ & 16 & 6403 & Szagun (2001) \\
Chantal & & $1 ; 10,8-2 ; 11,29$ & 29 & 9241 & Müller \& Kupisch (2003) \\
Elisa & Italian & $1 ; 10,4-2 ; 2,23$ & 8 & 1011 & Tonelli Corpus \\
Gregorio & & $1 ; 7,17-2 ; 0,28$ & 8 & 904 & Tonelli Corpus \\
Marco & & $1 ; 5,4-2 ; 1,27$ & 19 & 4697 & Tonelli Corpus \\
Martina & $1 ; 7,18-2 ; 7,15$ & 13 & 3018 & Calambrone Corpus \\
\hline \hline
\end{tabular}

size, I also indicated the total number of child utterances (yes and no were counted only once per recording, incomprehensible utterances and sounds like $h m, n e, a u$, etc. were excluded).

\section{Analysis}

In the analysis, I concentrated on overall rates of determiner use vs. determiner omission. Since there were differences in the total number of nouns produced in each recording and by each child, a simple count of determiners would have been misleading. Hence, for each recording I determined the number of contexts, in which an article or another determiner should have been used. Rates of determiner omission were then calculated by dividing the total number of contexts in which a determiner was omitted although it should have been used ("bare nouns", henceforth BNs) by the total number of nouns preceded by articles or other determiners. For example, utterances such as gatto "cat" or ecco gatto "here is cat" were counted as BNs. I included DPs containing prenominal determiners other than articles in the counts (e.g. demonstratives and quantifiers). Following the analyses in Giorgi and Longobardi (1991) and Lyons (1999), possessive pronouns were coded as adjectives in Italian and as determiners in German (see above). The procedure takes into account the baseline difference between German and Italian because contexts in which the noun is allowed to occur without a determiner in the adult language (plural and mass nouns and some singular nouns) were not included when establishing the rate of omission. Examples for such occurrences are provided in (11).

(11) a. Ge. Eis "ice cream" $(1 ; 10,8)$, Schuhe "shoes" $(1 ; 10,30)$, Papier maln "paper draw" $(2 ; 3,17)$, mach Wasser hier "make water here" $(2 ; 4,7)$, da Gummibärchen "there gummi bears" $(2 ; 4,21)$

b. It. acqua "water" $(1 ; 10,30)$, dadi "shoes" $(1 ; 10,30)$, formaggio quello "cheese that" $(2 ; 0,11)$, in cucina "in (the) kitchen" $(2 ; 7,13)$

(all examples are from the Carlotta-corpus, see below)
Besides the higher number of target-like bare nouns in German, there are two further reasons for excluding contexts like (11) from the category of (non-target-like) BNs. One is that the number of contexts for such targetlike bare nouns depends on the play situation (e.g. cooking typically involves a lot of mass terms). The inclusion of all bare nouns, regardless of grammaticality, would have created the risk of underestimating the rate of article use in obligatory contexts. Last, many mass and plural nouns in the early recordings are ambiguous between a specific and a non-specific interpretation, especially when they occur in isolation, as in (11). In fact, many of the objects the children refer to are situationally identifiable. However, this does not necessitate their conceptualization as specific object. To give an example, in a breakfast situation with butter on the table, we may choose to ask Could you give me butter? instead of Could you give me the butter? Bare nouns may also be ambiguous between a singular and a plural reading. For example, the German noun Gummibärchen "gummi bears" may be singular or plural. Such nouns are indeed "uncodable" with respect to article omission.

I further excluded proper names, one-to-one imitations, partial imitations (e.g. when the adult produces $a$ cat, and the child repeats $c a t$ ), fully unintelligible noun phrases and nouns that followed unintelligible speech.

In some instances, the children uttered vowels before Italian nouns, especially [e], [a], [ə], as illustrated in (12a). Following Bottari et al. (1993/1994), I interpreted these instances as precursors of the target articles. They are morphologically unspecified determiners, but should not be counted as omissions because they indicate the child's awareness of the necessity to fill the determiner position. Hereafter, I shall refer to them as FILLERS. In the German corpora, there are instances of incomplete forms as well, e.g. [ai] "a" and [de] "the". ${ }^{7}$ These represent the target forms more clearly, as they are marked as

7 Reduced articles like de are commonly used in some German dialects. However, the children grew up in Northern Germany and were not exposed to such forms, as Kupisch (2004) has shown in an analysis of the input to the child. Note, however, that articles are commonly reduced in contractions of prepositions and articles. 


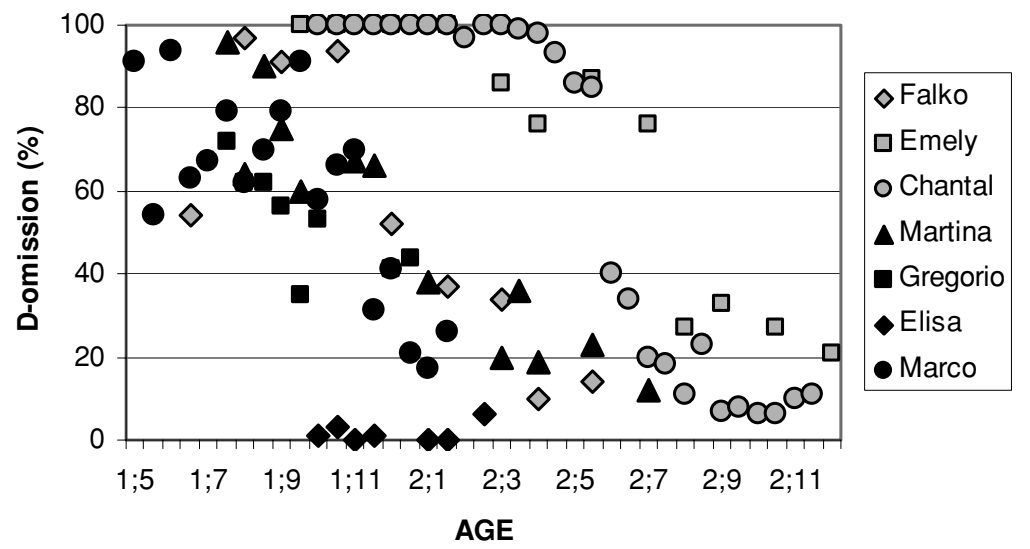

Figure 1. Rate of D-omission, monolingual German and monolingual Italian children.

(in)definite, although not for case and number. (In the following examples, MOT and FAT stand for "mother" and "father", GRE for "Gregorio" and FAL for "Falko".)

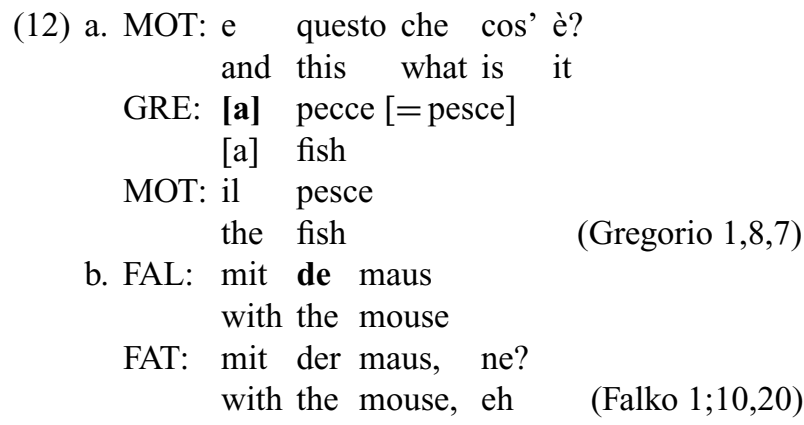

Note that the analysis was a purely syntactic one. That is, attention was paid to whether a determiner was provided in contexts where it is obligatory. It was of no relevance whether the supplied form was morphologically correct or not.

\section{Results}

As indicated in Table 3, the corpora varied with respect to the number of recordings conducted during a onemonth period and with respect to the age span covered. To compare the children in terms of age, I established two intervals within each one-month-period. The recordings were represented within the first interval, if they took part between the first and the 15th day in terms of child age (e.g. between 2;3,1 and 2;3,15), and within the second interval, if they took part between the 16th and the 31 st day. If there existed three recordings representing one single month (e.g. with Marco), the data from the two recordings closest in time were collapsed. The results are shown in the scatter plot in Figure 1. Grey symbols are representative of German children and black symbols are representative of Italian children. I discarded the percentages representing
Falko at 1;4 and 1;5 and Emely between 1;4 and 1;8, as there were less than 5 codable noun-tokens (excluding mass and plural terms).

Figure 1 indicates that the monolingual Italian children start to use articles and article-like fillers at a noticeably earlier age than the monolingual German children. At the same time, there is individual variation within languages. For instance, Falko is the fastest German learner whose values come close to those of the monolingual Italian children. Among the Italian children, Elisa is a child with exceptionally high values. Despite individual differences, however, there is a clear overall contrast between the two languages. ${ }^{8}$

\section{The bilingual children and their degree of language balance}

\section{The bilingual children}

In the following, I examine four longitudinal studies of German-Italian bilingual children in terms of their language balance. The period analyzed ranges from the earliest recordings available until 3;0, which corresponds to the period during which articles are usually acquired. All children were raised in bi-national families in Hamburg, Germany. All have German-speaking fathers and Italian-speaking mothers. Marta's mother is bilingual but speaks Italian to her daughter. The families of Carlotta and Marta spoke Italian at home to strengthen the language without community support. The recordings

\footnotetext{
8 It should be noted that the exceptionally low rate of omission for the child Falko at the age of $1 ; 6$ is due to a single token (ein fant "an elephant"), which he repeatedly used with a determiner (six times). However, no other data point that indicates article omission below $80 \%$ involves a type-token ratio of 1 for nouns.
} 
Table 4. Overview of the bilingual corpora.

\begin{tabular}{|c|c|c|c|c|c|c|c|}
\hline \multirow{2}{*}{$\begin{array}{l}\text { Bilingual } \\
\text { corpora }\end{array}$} & \multirow[b]{2}{*}{ Languages } & \multirow[b]{2}{*}{ AGE-span } & \multicolumn{2}{|c|}{$\begin{array}{l}\text { Number of } \\
\text { recordings }\end{array}$} & \multicolumn{2}{|c|}{$\begin{array}{l}\text { Total number } \\
\text { of child UTT }\end{array}$} & \multirow[b]{2}{*}{ Origin } \\
\hline & & & GE & IT & GE & IT & \\
\hline Carlotta & German-Italian & $1 ; 8 ; 18-2 ; 11,27$ & 25 & 24 & 3464 & 3307 & Müller et al. $(2002,2006)$ \\
\hline Jan & German-Italian & $2 ; 0,11-3 ; 0,10$ & 14 & 14 & 2730 & 1603 & \\
\hline Lukas & German-Italian & $1 ; 8,14-2 ; 11,26$ & 24 & 24 & 4867 & 3488 & \\
\hline Marta & German-Italian & $1 ; 6,26-2 ; 11,29$ & 30 & 30 & 2949 & 4403 & \\
\hline
\end{tabular}

were conducted bi-monthly for approximately 30 minutes in each language. The children were videotaped while playing with the interlocutors, who were native speakers of the respective languages. All corpora were collected in a project on early bilingualism comparing German-Italian and German-French children, conducted by Natascha Müller. ${ }^{9}$ An overview is presented in Table 4.

\section{Establishing language balance and making predictions}

\section{Selection of criteria}

Although there are numerous references to dominance in the literature on bilingual acquisition (e.g. Pfaff, 1992; Schlyter, 1993, 1994; Schlyter and Håkansson, 1994; Döpke, 1998; Meisel, 2001; Granfeldt, 2003), there is still neither a uniform definition nor a common way to measure it. In other words, the concept of language dominance is still a pre-theoretical one. In this article, language dominance is understood as the situation in which one of the languages of a bilingual child is further developed than the other. Following Grosjean (1982), I conceive of language dominance as a matter of degree rather than a binary notion, and, as many studies have reported (e.g. Leopold, 1978; Berman, 1979), there may be shifts on this continuum. In fact, there is hardly any bilingual child that has not, in some sense, one dominant language. As Grosjean (1982, p. 235) notes "balanced bilinguals, those who are equally fluent on both languages, are probably the exception and not the norm". The question that is

\footnotetext{
9 The research project has been funded by the German Science Foundation (DFG) as part of the Research Centre on Multilingualism in Hamburg. Data collection and transcription started before funding was granted. I would like to express our gratitude to the researchers involved in data collection and to the University of Hamburg for a research grant during the pilot phase of the project. Members of the research team were: Katja Cantone (lacantone@hotmail.com), Tanja Kupisch (tanja-kupisch@gmx.de), Katrin Schmitz (km7schmitz@yahoo.de); cf. Müller et al. (2002, 2006). Address for correspondence: Prof. Dr. Natascha Müller, Bergische Universität Wuppertal, Fachbereich A Romanistik, Gaußstraße 20, D-42119 Wuppertal, Germany; nmueller@uniwuppertal.de.
}

particularly interesting is, hence, not whether or not a child is balanced but rather to what extent $\mathrm{s} / \mathrm{he}$ is balanced.

Recently, researchers have started to evaluate measures of language dominance. Some criteria were argued to be conceptually dubious. For instance, De Houwer (1990) counted the number of pauses under the assumption that more pauses may be associated with less proficiency (see Genesee et al., 1995 for criticism). The MLU is the most hotly debated of all criteria, but at the same time the most successful one, as it is adopted in all studies (see De Houwer, 1990 for criticism). Furthermore, it has been proposed that one should distinguish between criteria that are associated with quantitative aspects and qualitative aspects of bilingual development, or performance and competence, but there is no common agreement, yet, on which criteria belong to the former group and which to the latter. For instance, Müller and Kupisch (2003) consider MLU and upper bound; i.e. the longest utterance in a recording (henceforth abbreviated as UB), to be qualitative criteria, while Bernardini and Schlyer (2004) consider them quantitative criteria. However, since all production data is essentially performance data, it is questionable whether we should draw any such distinction at all. Also, Bernardini and Schlyter's qualitative criteria, namely the point of acquisition of functional categories like CP, IP and DP, may be considered problematic as measures of dominance because there is cross-linguistic variation in the emergence of functional categories, as I have shown for articles in the previous section. Therefore, this criterion should only be used in comparing bilingual children to monolinguals.

Despite apparent shortcomings of measures of dominance, there is a need to examine language balance systematically. The present analysis is adjusted to the studies by Genesee et al. (1995) and Paradis et al. (2003) as they have included the broadest spectrum of measures. I make reference to the following five criteria: MLU, UB, the number of utterances per 30 minutes of recording (UTT), and the increase of the noun and verb lexicon. Unlike in the above studies, though, noun and verb types are counted instead of word types in general because of the greater sample size of this study. The MMU (amount of 
Table 5. Dominance measure for the bilingual children before the age of 2;0.

\begin{tabular}{|c|c|c|c|c|c|c|c|c|c|c|c|}
\hline & $\begin{array}{l}\text { MLU } \\
\text { GE }\end{array}$ & $\begin{array}{l}\text { MLU } \\
\text { IT }\end{array}$ & $\begin{array}{l}\text { UB } \\
\text { GE }\end{array}$ & $\begin{array}{l}\text { UB } \\
\text { IT }\end{array}$ & $\begin{array}{l}\text { UTT } \\
\text { GE }\end{array}$ & $\begin{array}{l}\text { UTT } \\
\text { IT }\end{array}$ & $\begin{array}{l}\text { NOU } \\
\text { GE }\end{array}$ & $\begin{array}{l}\text { NOU } \\
\text { IT }\end{array}$ & $\begin{array}{l}\text { VER } \\
\text { GE }\end{array}$ & $\begin{array}{l}\text { VER } \\
\text { IT }\end{array}$ & Index \\
\hline CAR & 1.4 & 1.3 & 3 & $2_{3 \mathrm{ge}}$ & $53_{4 \mathrm{it}}$ & 90 & $26_{\text {sit }}$ & 70 & $12_{5 \mathrm{it}}$ & 26 & $2.2_{\mathrm{it}}$ \\
\hline JAN & - & - & - & - & - & - & - & - & - & - & - \\
\hline LUK & 1.0 & 1.1 & 2 & 2 & 155 & $67_{5 \mathrm{ge}}$ & 77 & 74 & 13 & $6_{5 \mathrm{ge}}$ & $2.0_{\mathrm{ge}}$ \\
\hline MAR & $1.2_{\mathrm{lit}}$ & 1.4 & $2_{4 \mathrm{it}}$ & 4 & $32_{5 \mathrm{it}}$ & 86 & $16_{\text {5it }}$ & 57 & $1_{5 \mathrm{it}}$ & 19 & $4.0_{\mathrm{it}}$ \\
\hline
\end{tabular}

Table 6. Dominance measure for the bilingual children between 2;0 and 2;5.

\begin{tabular}{|c|c|c|c|c|c|c|c|c|c|c|c|}
\hline & $\begin{array}{l}\text { MLU } \\
\text { GE }\end{array}$ & $\begin{array}{l}\text { MLU } \\
\text { IT }\end{array}$ & $\begin{array}{l}\text { UB } \\
\text { GE }\end{array}$ & $\begin{array}{l}\text { UB } \\
\text { IT }\end{array}$ & $\begin{array}{l}\text { UTT } \\
\text { GE }\end{array}$ & $\begin{array}{l}\text { UTT } \\
\text { IT }\end{array}$ & $\begin{array}{l}\text { NOU } \\
\text { GE }\end{array}$ & $\begin{array}{l}\text { NOU } \\
\text { IT }\end{array}$ & $\begin{array}{l}\text { VER } \\
\text { GE }\end{array}$ & $\begin{array}{l}\text { VER } \\
\text { IT }\end{array}$ & Index \\
\hline CAR & $2.0_{1 \mathrm{it}}$ & 2.4 & 5 & 5 & 119 & $142_{\text {lge }}$ & $108_{3 \mathrm{it}}$ & 176 & 63 & 60 & $0.6_{\mathrm{it}}$ \\
\hline JAN & 2.1 & $1.5_{2 \mathrm{ge}}$ & 7 & $4_{4 \mathrm{ge}}$ & 155 & $104_{3 \mathrm{ge}}$ & 66 & $56_{1 \mathrm{ge}}$ & 64 & $22_{5 \mathrm{ge}}$ & $3.0_{\mathrm{ge}}$ \\
\hline LUK & 1.8 & 1.9 & 6 & $5_{1 \mathrm{ge}}$ & 181 & $144_{\text {Ige }}$ & $190_{\text {lit }}$ & 213 & 83 & 84 & $0.2_{\mathrm{ge}}$ \\
\hline MAR & $1.9_{1 \mathrm{lit}}$ & 2.2 & $5_{1 \mathrm{it}}$ & 6 & $129_{3 \mathrm{it}}$ & 177 & $62_{5 i t}$ & 152 & $19_{5 \mathrm{it}}$ & 66 & $3.0_{\text {it }}$ \\
\hline
\end{tabular}

multi-morphemic utterances) is not counted because the criterion loses significance with older children, although it may be suitable for children around the age of two.

\section{Analysis}

The children's language balance has been measured within three periods: (i) before the age of 2;0, (ii) between 2;0 and $2 ; 5$, and (iii) between $2 ; 6$ and $3 ; 0 .{ }^{10}$ Unfortunately, not all children have been recorded from the same age and there is no first period data for the child Jan. In the case of MLU, UB and UTT, the values have been established for each language in each period by taking a mean. ${ }^{11}$ Regarding the noun and the verb lexicon, which have been measured incrementally, I have considered the value of the last recording pertaining to the period. The raw data for the dominance measures have been evaluated together by the research group (Cordes, 2001; Loconte, 2001; Müller and Kupisch, 2003; Müller et al., 2006). German and Italian were then compared to each other to establish the magnitude of the inter-language contrast. The language with the smaller value was indexed. If the lower value

10 These age groupings have been selected because they may be considered stages in the acquisition of determiners. Before age 2;0, DPs (bare or with a determiner) mostly occur in isolation and their function is limited to naming and deictic reference. After age 2;0, DPs start to be used as arguments of lexical verbs. After age 2;5, determiner omission in obligatory contexts has decreased to a low percentage (Kupisch, 2004).

11 Some adjustment was necessary. As not all recordings were of equal length, the number of utterances per session have been subdivided to the duration/minutes of the recording and multiplied by 30 . In calculating the MLU, we tried to minimize typological differences by counting Italian null subjects as words. In German noun compounds, each component was counted as a separate word. Particle verbs were counted as two words. deviated $10 \%$ or less from the higher value, the index was deleted; if the deviation ranged between $11 \%$ and $20 \%$, an index of 1 was assigned; if the smaller value deviated between $21 \%$ and $30 \%$, an index of 2 was assigned, etc. The maximum index of 5 was assigned when the deviation exceeded $50 \%$. To illustrate, if the child reached an MLU of 3.4 in one language and of 3.6 in the other, no index was assigned. If the German MLU was 2.1 and the Italian MLU 1.5 , the Italian value 1.5 was indexed as $1.5_{2 g e}$, which means that the higher value was obtained in German, and the Italian value differed from it between $21 \%$ and $30 \%$. An overall index was calculated for each acquisition stage by taking a mean of all criteria. If there was alternation with respect to the language carrying the index, the two counterbalanced each other.

\section{Results}

The results are illustrated in Tables 5 through 7 and visualized in Figure 2. The two children Jan and Lukas show higher values in German throughout, but the interlanguage contrast for Jan (indices between 3 and 4) by far exceeds that for Lukas (indices of 2 or below 2). Marta shows higher values in Italian throughout, and Carlotta predominantly in Italian. The contrast is larger in the case of Marta (indices between 3 and 4) than in the case of Carlotta (2.2 and below 1). Note also that Carlotta and Lukas have relatively high indices only during the early phase. We may conclude that these two children are quite balanced, Carlotta with a tendency towards higher values in Italian, Lukas with a tendency towards German. Marta and Jan are fairly unbalanced, Marta with Italian as her stronger language, and Jan with German as his stronger language. 
Table 7. Dominance measure for the bilingual children between 2;6 and 2;11.

\begin{tabular}{|c|c|c|c|c|c|c|c|c|c|c|c|}
\hline & $\begin{array}{l}\text { MLU } \\
\text { GE }\end{array}$ & $\begin{array}{l}\text { MLU } \\
\text { IT }\end{array}$ & $\begin{array}{l}\text { UB } \\
\text { GE }\end{array}$ & $\begin{array}{l}\text { UB } \\
\text { IT }\end{array}$ & $\begin{array}{l}\text { UTT } \\
\text { GE }\end{array}$ & $\begin{array}{l}\text { UTT } \\
\text { IT }\end{array}$ & $\begin{array}{l}\text { NOU } \\
\text { GE }\end{array}$ & $\begin{array}{l}\text { NOU } \\
\text { IT }\end{array}$ & $\begin{array}{l}\text { VER } \\
\text { GE }\end{array}$ & $\begin{array}{l}\text { VER } \\
\text { IT }\end{array}$ & Index \\
\hline CAR & 3.0 & 3.1 & $10_{\text {lit }}$ & 12 & 120 & 110 & $259_{1 \mathrm{lit}}$ & 292 & 163 & $101_{3 \mathrm{ge}}$ & $0.2_{\mathrm{ge}}$ \\
\hline JAN & 2.7 & $1.9_{5 \mathrm{ge}}$ & 9 & $5_{4 \mathrm{ge}}$ & 179 & $90_{4 \mathrm{ge}}$ & 174 & $116_{3 \mathrm{ge}}$ & 167 & $38_{5 \mathrm{ge}}$ & $4.2_{\mathrm{ge}}$ \\
\hline LUK & 3.6 & 3.4 & 14 & 13 & 200 & $142_{2 \mathrm{ge}}$ & 443 & 401 & 218 & $149_{3 \mathrm{ge}}$ & $1.0_{\mathrm{ge}}$ \\
\hline MAR & $2.7_{1 \mathrm{it}}$ & 3.2 & $7_{1 \text { it }}$ & 10 & $116_{3 \mathrm{it}}$ & 186 & $120_{5 \mathrm{it}}$ & 275 & $46_{5 i t}$ & 125 & $3.0_{\mathrm{it}}$ \\
\hline
\end{tabular}

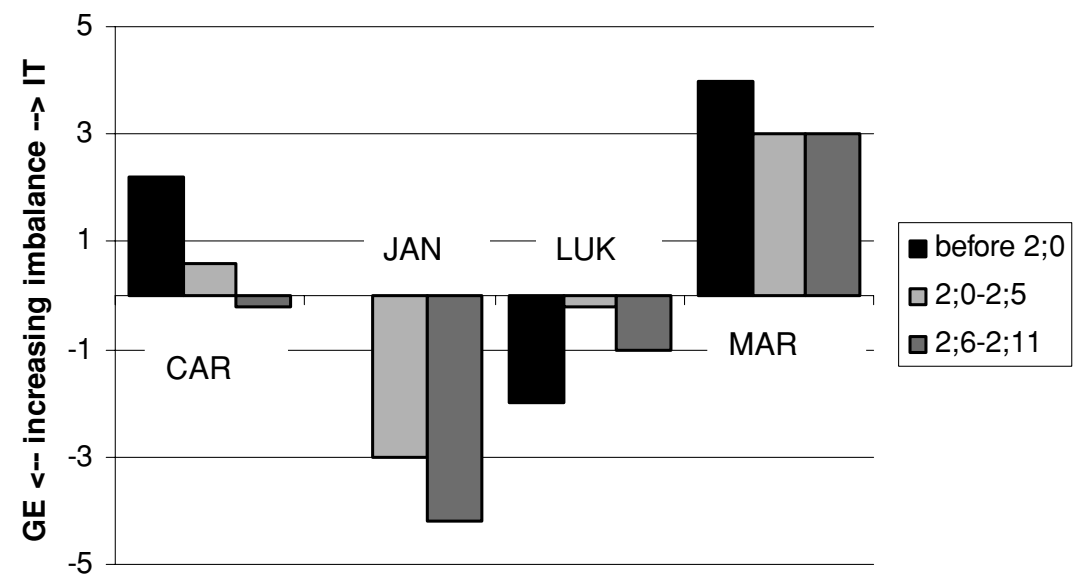

Figure 2. Language balance in the German-Italian bilingual children.

It is worth pointing out that two of the measures do not exactly pattern with the others, namely verb types and UTT. More particularly, these measures result in higher inter-language contrasts generally. The deviance with respect to UTT may be due to some children's preference to speak in one language. As for verb types, the explanation could be that German has a high number of particle verbs, which children use productively from an early age (e.g. hinfliegen "fly to", wegfliegen "fly away", rüberfliegen "fly across", durchfliegen "fly through", etc.), while the Italian equivalent often constitutes a single verb type. This would also account for the fact that even Carlotta, who tends towards higher values in Italian, uses a higher number of German verb types during the third stage.

\section{Predictions for the occurrence of language influence}

In this paper, I am adopting the concept of language influence developed by Paradis and Genesee (1996). Accordingly, language influence is SYSTEMIC, if it is sustained over a period of time and causes differences in a bilingual's rates of development in comparison with a monolingual's. The phenomenon may manifest itself in ACCELERATION, which means that a grammatical property emerges in the grammar EARLIER than would be usual in monolingual acquisition, and in a DELAY, if a grammatical property emerges in the grammar
LATER than would be usual in monolingual acquisition. Another possible manifestation is TRANSFER, defined as "the incorporation of a grammatical property into one language from the other" (ibid., p. 3). As far as I can see, this third manifestation of influence can be seen most clearly in domains where languages show no overlap, e.g. if one language allows null subjects and the other language does not allow them. I further take into account the development of a grammatical phenomenon in the bilingual's two languages compared to each other. More specifically, if a bilingual individual behaves like a monolingual in each of his/her languages, we expect him/her to show the same differences in the rate of determiner acquisition in the two languages that are found in monolingual children.

Hulk and Müller (2000) (see also Müller and Hulk, 2001) have formulated predictions for when language influence (which they refer to as CROSS-LINGUISTIC INFLUENCE) is to be expected, namely

(i) if the phenomenon involves the interface between two modules of grammar, specifically the interface between syntax and pragmatics;

(ii) if the languages instantiate some overlap of the two languages at the surface level.

The authors have explicitly argued that language influence is not due to language dominance, but can be accounted 
for by language internal factors alone. They further claim that the direction of language influence can be predicted. If there is a language A that provides evidence for two different analyses with respect to a grammatical domain, one of these analyses can be identified as the default analysis (in the sense of Roeper's (1999) MINIMAL DEFAULT GRAMMAR). If the child is simultaneously exposed to input from a language B which ONLY presents evidence for the default analysis, the default analysis is reinforced and influence from language $\mathrm{B}$ to language $\mathrm{A}$ is to be expected. Some problems with this account must be noted, though. Unsworth (2003) has criticized Hulk and Müller's (2000) proposal, because it predicts language influence where it does not occur, e.g. in the case of root infinitives in bilingual children acquiring German and English. In other words, it is not restrictive enough. In the present case, another issue arises. With respect to DPs, Roeper (1999) has identified the BN-GRAMMAR (or NP-GRAMMAR) as the default analysis, which is intuitively plausible, as it involves less structure than a DP-grammar. However, in the case of German and Italian DPs, both languages provide evidence for the NP-grammar AND the DP-grammar so that the direction of influence cannot be predicted. Thus, syntactic criteria alone lead no further here. Müller et al. (2002) have proposed instead that children prefer less complex analyses to more complex analyses. ${ }^{12}$ The analysis of article use in German and Italian presented above gives principled reasons for the assumption that German DPs are more complex. Thus, if the direction of influence can be predicted in terms of complexity, Italian is expected to influence German.

Let us now turn to the question of what is to be expected in terms of language influence under either assumption, i.e. the assumption that language dominance plays the crucial role versus the assumption that complexity plays the crucial role.

One hypothesis to be tested is whether language influence is determined by language dominance alone. I will refer to this hypothesis as DOMINANCE HYPOTHESIS (DH). The DH makes two predictions. First, influence should be restricted to unbalanced children, i.e. only Jan's and Marta's development should be subject to it. In contrast, dominance should not be observed with Carlotta

12 The definition of complexity adopted in Müller et al. (2002) is based on a proposal by Jakubowicz (1999) and defined in terms of syntactic and semantic factors. For example, a grammatical phenomenon is less complex if it must be present in every sentence. It is more complex if is it required in only some sentences. In the latter case, it expresses semantic content. The present contribution suggests that syntactic and semantic criteria are insufficient to predict the direction of language influence because article use is contingent on semantic factors in both German and Italian, and that a more appropriate definition of complexity must include consideration of phonological, morphological and pragmatic factors as well. and Lukas because they are balanced. Second, as the stronger language is expected to influence the weaker one, we would expect Jan's development in Italian to be delayed in comparison to monolingual children and Marta's development in German to be accelerated in comparison to monolingual children. In the comparison of the bilinguals' two languages, Carlotta and Lukas should show a difference in the rate of determiner acquisition between German and Italian. Moreover, Marta's Italian may influence German to the extent that German articles are acquired at the same rate as Italian articles (but not faster). Jan's German may influence his Italian to the extent that Italian articles are acquired at the same rate as German articles (but not slower).

The alternative hypothesis is that language dominance is determined by language internal factors, here defined in terms of complexity. I will refer to this alternative view as the COMPLEXITY HYPOTHESIS (CH). It was demonstrated that Italian is more beneficial to determiner acquisition than German. In this sense, German determiners may be considered more complex. Now, if language influence were driven by complexity alone, and if children preferred less complex analyses to more complex analyses, Italian is predicted to have an accelerating effect on article acquisition in German, independently of balance.

With respect to Marta, both hypotheses predict the same outcome, namely that Italian should have a positive effect on German. Thus, Marta's data allows no falsification of either hypothesis. With respect to Jan, DH predicts a negative effect of German on Italian, while $\mathrm{CH}$ predicts the contrary. For the two balanced children, $\mathrm{CH}$ predicts language influence from Italian to German, while DH predicts no influence.

\section{The acquisition of determiners in bilingual children}

The following two sections report the results of the analysis of article omission in children acquiring German and Italian. I begin by comparing the two languages of each bilingual child. I then compare the evolution of determiners in the bilingual data and in the monolingual data. The analysis is performed according to the same criteria as in the monolingual study. Mixed DPs are excluded from the counts.

\section{The two languages compared to each other}

\section{The two balanced children}

Figures 3 and 4 indicate the change in the rate of determiner omission measured as a function of age for Carlotta and for Lukas. Except between the age of $2 ; 0$ and 2;4, when Lukas uses more articles in Italian, the children omit articles to a similar extent in both languages. Under the assumption that bilingual children have two autonomous grammatical systems, we would 


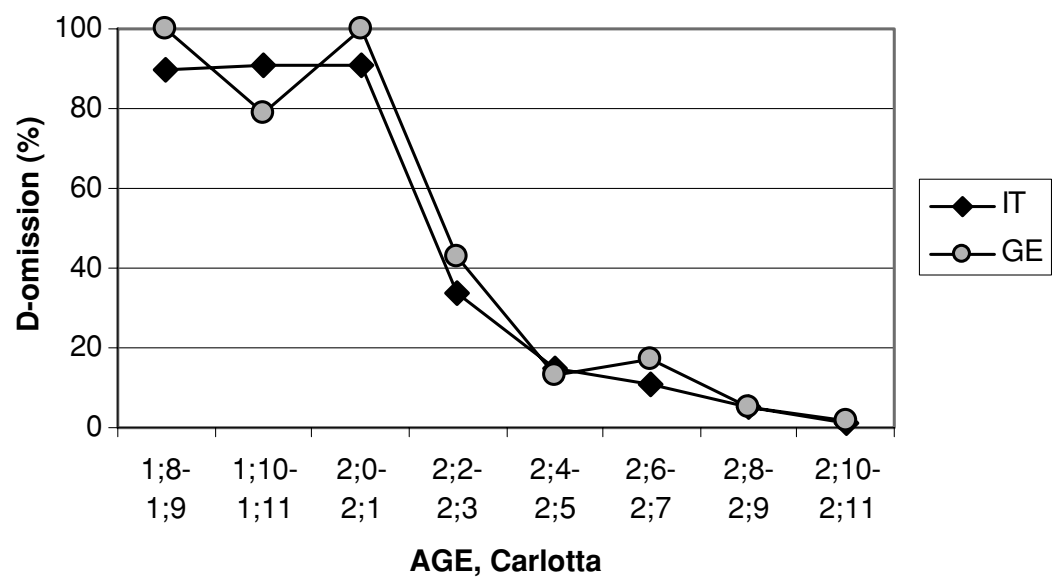

Figure 3. Rate of determiner omission in German and Italian, Carlotta (balanced).

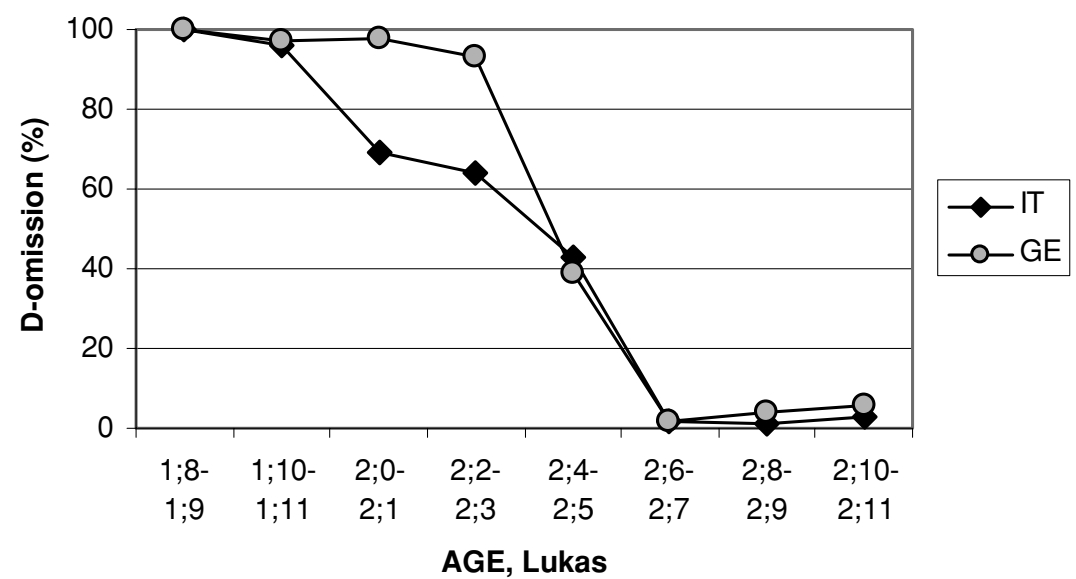

Figure 4. Rate of determiner omission in German and Italian, Lukas (balanced).

have predicted the development in Italian to be faster, which holds true only for Lukas between the ages of 2;0 and 2;4, a stage during which he is well balanced (see Table 4 above). I take the absence of a language contrast during the remaining stages of Lukas, and generally in the case of Carlotta, to be a first indication in favor of language influence.

\section{The two unbalanced children}

Figures 5 and 6 compare the rate of article omission in the German and Italian of the two unbalanced children, Jan and Marta. Figure 5 shows that Jan's rate of determiner omission is noticeably higher in Italian than in German. The rate of determiner omission in Marta's two languages is almost parallel, as illustrated in Figure 6. Again, if the absence of noticeable language contrast may be taken to be an indicator of language influence, the data for Marta speak in favor of influence. In contrast, for Jan, influence appears to be absent, because determiner omission does not decrease at the same rate in both languages. Also, unlike what is found for monolinguals, Italian is the language that displays the higher rate of determiner omission. One may object that an influence from German onto Italian does not necessarily imply that the two languages behave similarly. However, it is unlikely that German articles influence the development of Italian articles to such an extent that Italian articles occur notably later than German articles. Rather, if the latter is the case, it can be more plausibly related to the fact that Jan's Italian develops slowly in general.

So far, the data are suggestive of language influence in the case of all children, except for Jan. For the two hypotheses formulated above, $\mathrm{DH}$ and $\mathrm{CH}$, this would mean that both are disconfirmed, the former because there are balanced children who show influence, and the latter because there is one child whose German is not subject to language influence. Let us turn to the comparison with monolingual data, however, before drawing any final conclusions. This comparison will also be more revealing with respect to the DIRECTION of language influence, which may help to test the $\mathrm{CH}$ further. 


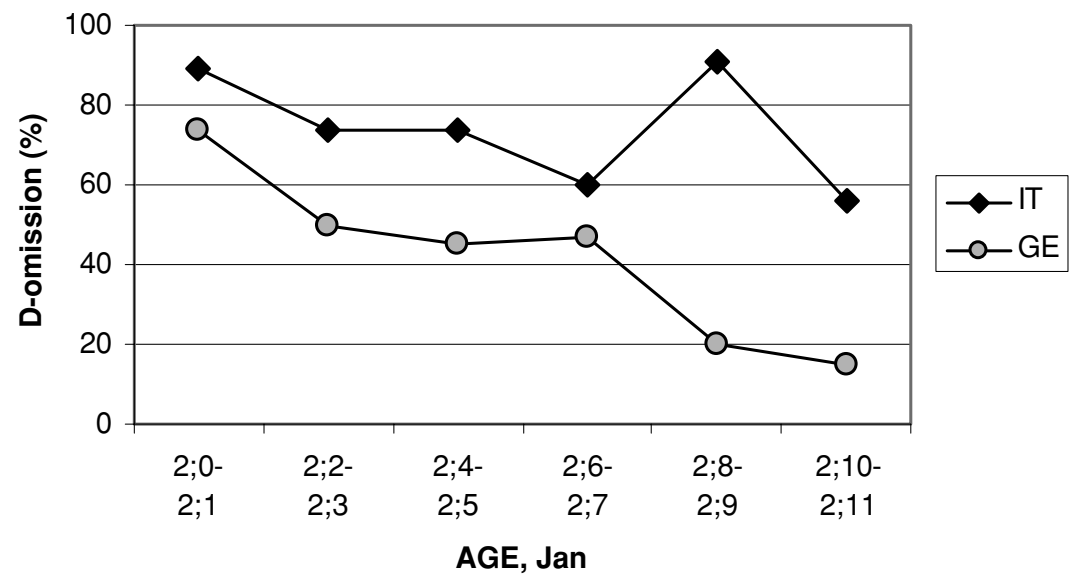

Figure 5. Rate of determiner omission in German and Italian, Jan (unbalanced).

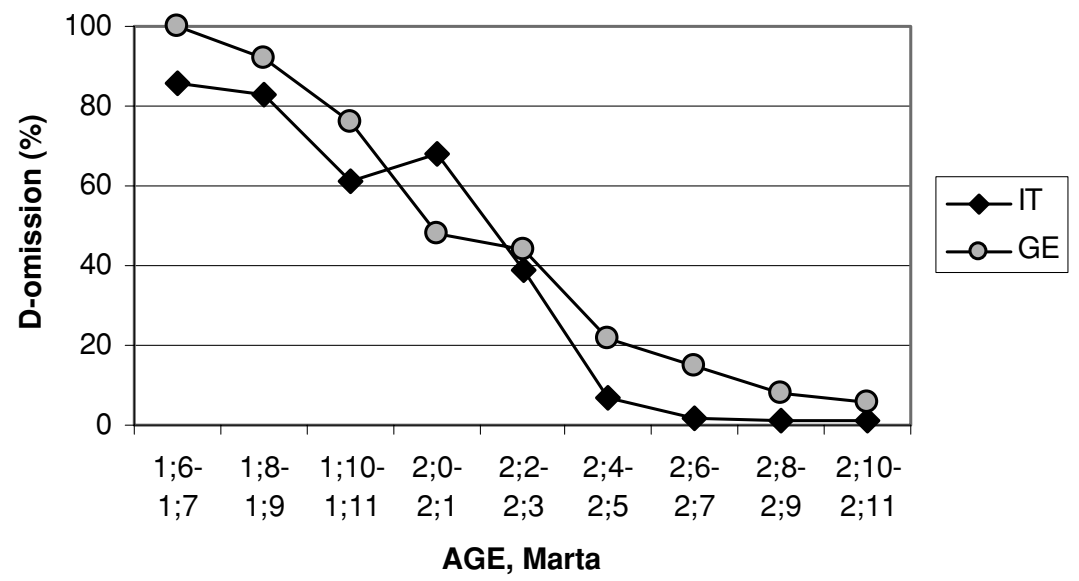

Figure 6. Rate of determiner omission in German and Italian, Marta (unbalanced).

\section{The bilingual children compared to monolingual children}

\section{Italian}

Figures 7 and 8 contrast the rate of determiner omission in the bilingual children's Italian with that of monolingual children. Figure 7 illustrates the two balanced bilingual children Carlotta and Lukas, who show similar patterns when compared to each other. Their values are lower compared to the monolingual children until $2 ; 3$, and similar to those of most monolingual children after that age. Thus, there appears to be a slight delay in both bilingual children's onset of article use in Italian. Figure 8 shows the rate of determiner omission in the two less balanced children Marta and Jan, indicating that the two children differ in their rate of omission. While Marta's values are most of the time similar to those of the monolingual children, Jan has noticeably lower values, except during the first recording at 2;0.
In sum, the analysis of the Italian data appears to indicate that the two balanced bilingual children are slightly behind monolingual children with respect to the onset of their use of Italian articles, and it cannot be excluded that this is caused by their simultaneous exposure to German. Jan's development of Italian determiners is delayed, while Marta patterns with monolingual children. The analysis suggests that the resemblance of bilingual development and monolingual development increases with growing dominance in Italian.

\section{German}

Figures 9 and 10 present the rate of determiner omission in the bilingual children's German compared to monolingual children. Unlike in Italian, all bilingual children are concordant with the fastest German learners in their acquisition of German determiners. Figure 9 includes the more balanced children Carlotta and Lukas. Their 


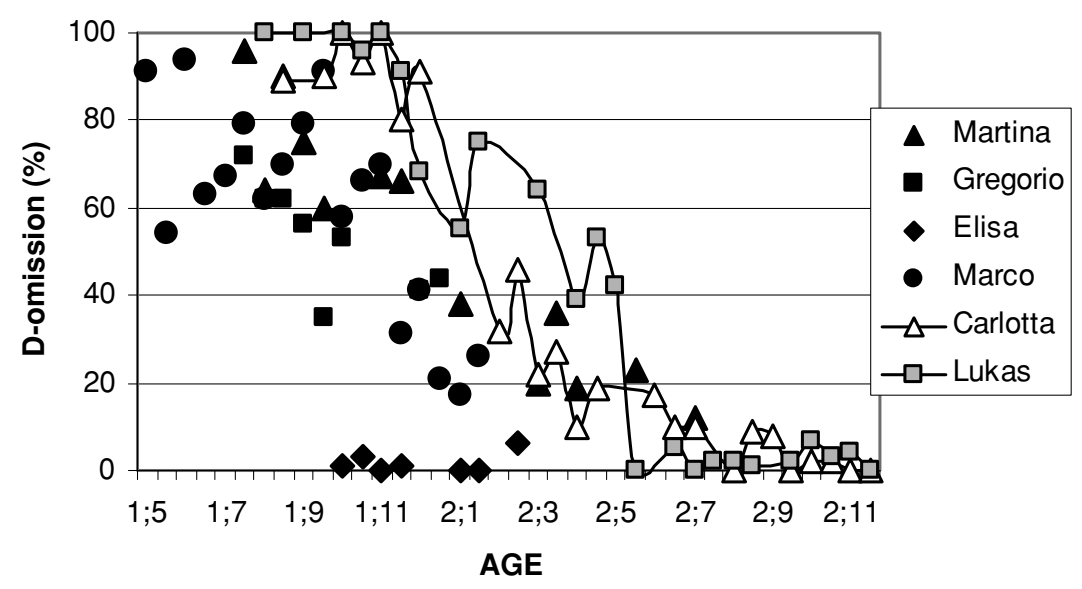

Figure 7. Rate of D-omission in Italian, the two balanced children compared to monolingual children.

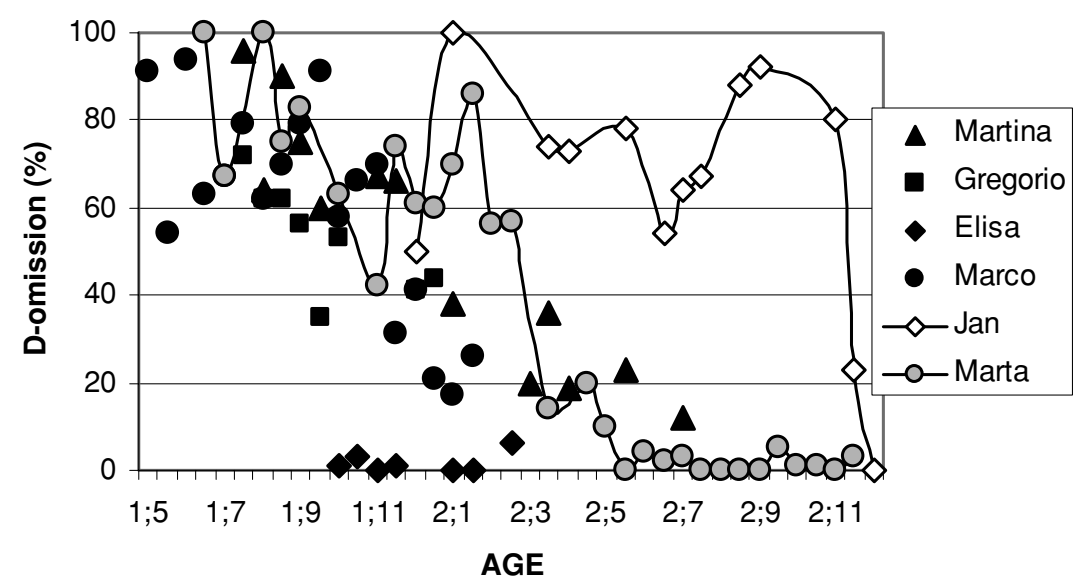

Figure 8. Rate of D-omission in Italian, the two unbalanced children compared to monolingual children.

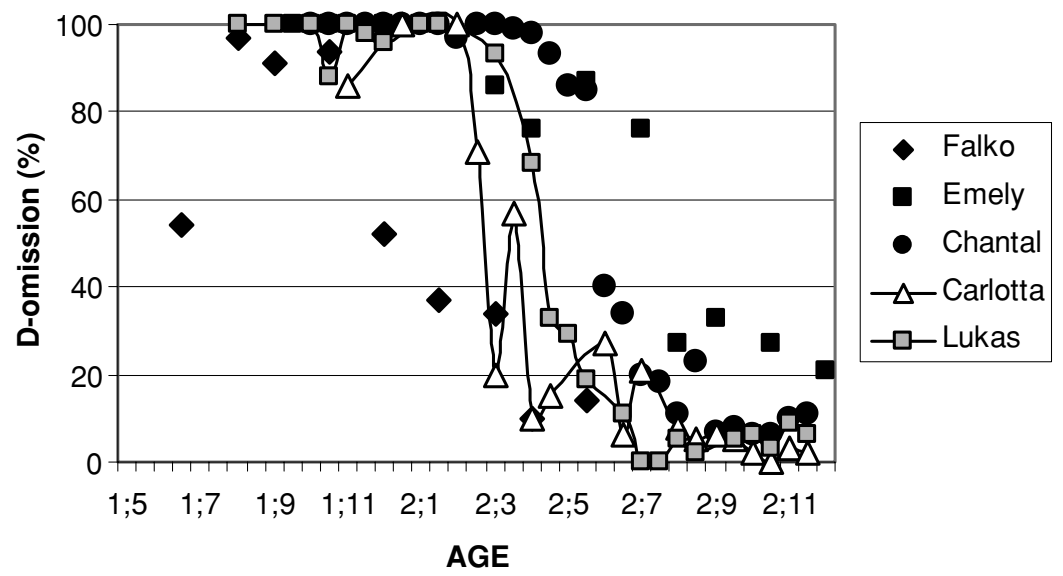

Figure 9. Rate of D-omission in German, the two balanced children compared to monolingual children. 


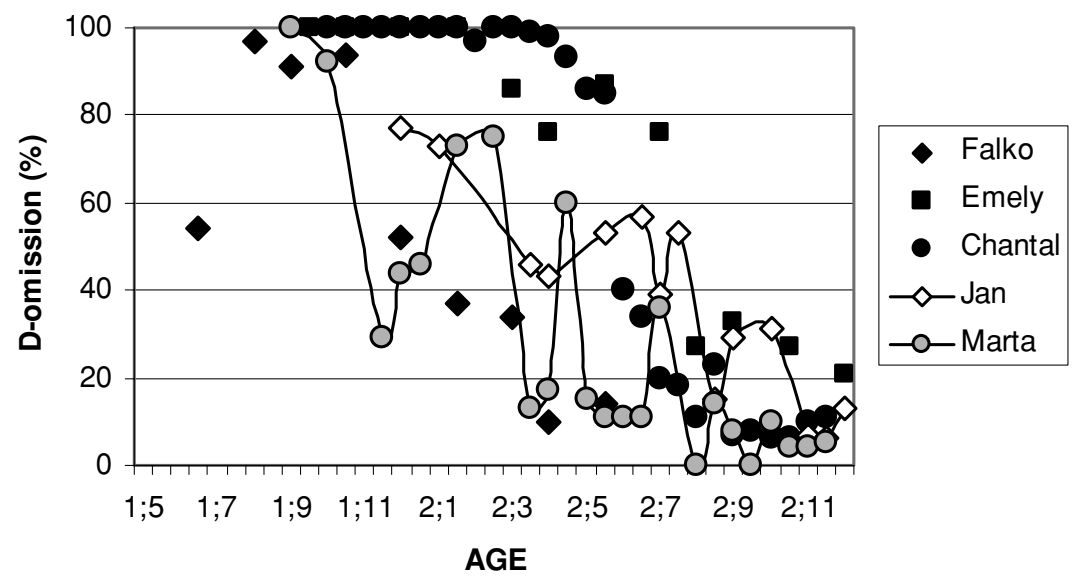

Figure 10. Rate of D-omission in German, the two unbalanced children compared to monolingual children.

usage rates exceed those of most monolingual children. Compared to each other, their course of development is strikingly similar, but with an earlier onset of article use in the case of Carlotta (mostly in the form of filler-articles). Figure 10 shows the development of the two unbalanced children Marta and Jan. Marta's rate of acquisition matches that of the fastest German learner, and she shows a noticeably earlier onset of article use than the monolingual children. For Jan, the onset of article use has been missed; his rate of development represents just the midway between the fastest and the slowest German learners.

Before concluding this section, I wish to discuss potential criticism that may be raised against an age-based comparison. There is no doubt that linguistic development is subject to individual variation, and I am fully aware of the fact that three longitudinal studies are insufficient to provide a representative account of determiner acquisition in a language. Thus, it may well be that the results obtained here will be contradicted by future research on the same topic. On the other hand, an MLU-based comparison appears to be even more problematic than an age-based comparison, because the MLU increase is dependent on article use, especially in children's earliest speech production where nouns constitute the largest word class. Furthermore, German and Italian data are not directly MLU-comparable, because of their different typological properties. Not all of these differences may be leveled out regardless of whether a word-based MLU or a morpheme-based MLU is chosen. Nevertheless, I have compared the children's MLUs at one particular point of their determiner development to see whether the outcome wOULD contradict the conclusions that have so far been drawn.

As children's repertoire of words and word classes increases with growing age, the suspected correlation between MLU and article use will decrease with growing age. To minimize the effect of a possible correlation of MLU and article use, children's MLUs should be compared at a late point in acquisition. I chose the point at which the children had reached the rate of $50 \%$ of determiner use in obligatory contexts (not all children have reached the commonly used criterion of $90 \%$ of use during the period analyzed). I excluded Elisa from the comparison, because her usage rate was already beyond $90 \%$ during the first recording at age 1;10,4 (MLU 3.5).

The result is presented in Table 8. The monolingual Italian children reach the $50 \%$ mark with lower MLU values than monolingual German children. The bilingual children reach the $50 \%$ mark of determiner use in Italian with higher MLU values than monolingual Italian children, but in German they do so with lower MLU values than monolingual German children. ${ }^{13}$

We may conclude this section by noting that only the child whose Italian developed rather slowly, i.e. Jan, showed a delay in determiner acquisition. The children whose development of Italian was normal only showed a slight delay in the onset of determiner use. The child whose Italian developed fast compared to German developed determiners within the range of monolingual children. As for German determiners, we may notice that all children whose Italian (determiner-)development was not delayed were further advanced in their development of German determiners than monolingual children of the same age.

13 If we look at the values for each child individually, those of Carlotta and Lukas may appear rather surprising, for the two are classified as balanced and argued to exhibit language influence. Still, they show a noticeable difference in their MLU values at the $50 \%$ mark. The explanations are the following: Carlotta, although being balanced in general, shows a fairly strong MLU contrast between ages $2 ; 0$ and $2 ; 5$; in Lukas' development, the $50 \%$ mark in article use coincided with a sudden increase in Italian MLU-values (from 2.0 to 2.6), but in German a comparable MLU increase occurs one month later. 
Table 8. Children's MLUs when reaching $50 \%$ of article use in obligatory contexts.

\begin{tabular}{llllllllll}
\hline \hline \multicolumn{3}{c}{ monolingual } \\
\hline IT & GRE & MARC & MART & mean & CAR & JAN & LUK & MAR & mean \\
MLU & 2.1 & 2.1 & 2.3 & 2.2 & 2.7 & 2.5 & 2.6 & 1.8 & 2.4 \\
GE & CHA & EME & FAL & mean & & & & & \\
MLU & 2.4 & 2.1 & 2.4 & 2.3 & 2.4 & 2.2 & 2.0 & 1.8 & 2.1 \\
\hline \hline
\end{tabular}

\section{Language influence from a qualitative perspective}

The study has indicated that children whose Italian develops normally or fast use German determiners more than monolinguals at the same stage of development. In qualitative terms, this may be taken to mean several different things: ${ }^{14}$

(i) bilinguals are less likely than monolinguals to omit determiners when these are required;

(ii) bilinguals are more likely than monolinguals to use determiners in optional contexts;

(iii) bilinguals overuse determiners in contexts where they would be used in Italian but not in German.

In the remainder of this section I discuss each of these possibilities. The quantitative study presented above has focused on examining determiner use in obligatory contexts. It was shown that bilinguals were less likely to omit determiners when these are required; i.e. (i) is borne out.

As for (ii), it must be clarified first what OPTIONALITY would mean here. I understand determiners to be optional when their use or omission has no implications, neither for the grammaticality, nor the meaning of the DP. As far as I can see, there is no such context in German, except, perhaps, with proper names, where monolingual German speakers of a Northern variety do not use articles themselves, but, at the same time, do not consider a DP such as die Maria to be ill-formed..$^{15}$ There are, in fact, a few occurrences of proper names with articles in all bilingual German corpora, but they are by far outnumbered by tokens without an article. Note also that we cannot rule out that the children heard other German speakers using articles with proper names. Hence, there is not enough evidence to allow me to take a definite stand with respect to (ii).

14 The importance of discussing this point was pointed out to me by an anonymous reviewer.

15 The difference in meaning is very subtle. Some speakers of High German perceive an ironic or even negative undertone when proper names are used with articles. In contrast, e.g. die Maria is widely used in southern varieties of German.
The most interesting possibility is (iii), i.e. the question whether children overuse determiners where they may occur in Italian but must not occur in German. I will refer to such cases as TRANSFER, because they would clearly indicate that a property from one language is incorporated into the other language where it does not exist. Of course, this definition looks at contexts of use in terms of both syntactic and semantic adequacy (syntactically, DPs and BNs are acceptable in both languages). In the comparison of German and Italian articles presented above, I mentioned the following contexts in which there exist contrasts:

(i) mass/plural nouns with non-specific reference (e.g. Tomaten und Käse kaufen/comprare dei pomodori e del formaggio "buy tomatoes and cheese")

(ii) generic noun phrases (e.g. er mag Wein/gli piace il vino "he likes wine")

(iii) inalienable possessions (e.g. blaue Augen haben/ avere gli occhi blu "have blue eyes")

(iv) possessive-marked nouns (e.g. meine Katze/il mio gatto "my cat")

With German mass and plural nouns an overuse of articles is most unlikely, because there exist no German translation equivalents of the Italian partitive and indefinite plural articles. It is conceivable that children may overuse German DEFINITE articles where Italian speakers use indefinite and partitive articles, but this is not borne out by the data. Of course, bilinguals do use definite articles before mass and plural terms, but this is indeed required with specific reference. Moreover, a large amount of German mass and plural terms that have no specific reference are zero-marked (see Kupisch, 2004 for details), which would speak against transfer.

Let us turn to generic utterances. These occur scarcely and fairly late in longitudinal studies (see also Serratrice, 2000). There are a few utterances in the data of Carlotta, illustrated in (13), which would suggest that generic contexts may be subject to transfer, but there are also zero-marked DPs with generic reference, as in (14). On the 
whole, the number of generic DPs is too low to substantiate a strong claim. (In (13), A = adult, CAR = Carlotta)

(13) a. A: das ist das krümelmonster/was macht der immer?

"That's the cookie monster what does he always do?"

CAR: die keksen essen the cookies eat

A: der isst, der isst sehr gerne kekse ne? "He eats, he likes to eat cookies a lot, doesn't he?"

(Carlotta 2;8,21)

b. wenn ich weine ich habe die tränchen when I cry I have the tears

(Carlotta 2;11,13)

(14) a. diese ist eh für - ist für weintrauben this is eh for is for grapes

(Carlotta 2;9,25)

b. das solln doch hunde gar nicht essn that should dogs not eat da(s) sind doch für katzen, brekkies that are for cats brekkies "Dogs shouldn't eat that, brekkies are for cats." (Lukas 2;9,18)

c. kann man das essn, temtamtaschntücher? [=Tempotaschentücher] can one that eat tissues

(Lukas 2;9,18)

By contrast, expressions with haben/avere "have" and nouns denoting inalienable possessions, such as eyes, hands, fingernails, hair, etc. are frequent in the data of Carlotta (12 tokens) and there is one instance in the corpus of Jan. All, and correctly so, lack the definite article. Examples are presented in (15).

(15) a. guck mal der hat lange haare look he has long hair

b. guck mal, braune haare hat sie

(Jan 2;7,28) look brown hair has she

(Carlotta 2;9,25)

c. ich, ich hab blonde haare aber sie auch I I have blond hair but she also

(Carlotta 2;9,25)

d. jetzt hab ich rote augen now have I red eyes

(Carlotta 2;11,27)

e. weil ich habe - weil ich habe, kleine hände because I have because I have small hands

(Carlotta 2;11,27)

The most insightful context for the question of potential transfer is that of possessive pronouns, as these occur frequently in all corpora. I extracted all contexts of prenominal possessive pronouns in German to see whether any of those is preceded by a definite article, as required in Italian. There is a single token in the corpus of Carlotta at 2;11,13 where she said die oma meine "the grandma mine" instead of meine Oma "my grandma". Interestingly, the possessive is also placed postnominally, as in Italian (the analysis in terms of a predicative use is implausible within the given context). In all other contexts, however, the possessive pronoun was not preceded by a definite article (Carlotta: 50 tokens, Jan: 34 tokens, Lukas: 76 tokens, Marta: 14 tokens). If we exclude kinship terms, which are used without definite articles in Italian, too, there remain 139 contexts of the type mein haus "my house", meine teddies "my teddies", with no traces of transfer from Italian.

To conclude this section, I would like to suggest that bilingual children acquiring Italian simultaneously with German use German articles more often in contexts where they are obligatory. Nevertheless, they do not overuse German articles in contexts where there are obligatory in Italian but where they must be absent in German. This indicates that the bilinguals examined here do not directly transfer Italian constructions into German, but are aware of the semantic conditions underlying article use in each language. Rather, the influence is indirect, i.e. the Italian input increases the bilingual child's early awareness of German articles. The assumption that the languages are equally complex in DP-syntax and at the syntax/pragmatics interface, as well as the absence of transfer at the syntax/semantics interface, suggest that phonological and frequency related factors are crucial. The latter assumption is, however, speculative and remains to be tested in future research.

\section{Summary and discussion}

\section{Summary}

The present study began by comparing the article systems of German and Italian, arguing that Italian is more beneficial to determiner acquisition than German. It was shown that these inter-language differences figure in different rates of determiner acquisition such that Italian children start to produce determiners at earlier ages and show lower rates of determiner omission. The results support the asymmetry between children acquiring a Germanic language and children acquiring a Romance language previously reported in the literature. Based on the findings, two questions were addressed: (1) Do bilingual children mirror the contrast found with monolingual children?; and, since (1) turned out to be false, (2) whether this can be attributed to language dominance or to a language internal factor.

Four bilingual children were then compared in terms of language balance. Two of the children may be classified 
as balanced (Carlotta and Lukas), and two as unbalanced (Jan and Marta), each with a different language as the stronger one. Carlotta and Lukas show a slight delay in the onset of determiner use in Italian, but pattern with monolingual children after the age of $2 ; 3 / 2 ; 4$, while they acquire German determiners faster than most monolingual German children. The delay in Italian is not as strong as the acceleration in German. Marta's development in Italian is consistent with that of monolingual learners, while she acquires German determiners relatively fast, although her German develops rather slowly in general. Jan's development of Italian determiners appears to stagnate after $2 ; 0$ and proceeds slowly compared to monolingual children, while his German determiners develop normally. $\mathrm{He}$ is the only child with a noticeable inter-language contrast in determiner omissions, and it is German and not Italian where omissions decrease more slowly. The results for Carlotta, Lukas, and Marta were interpreted in favor of cross-linguistic influence. The results of Jan, by contrast, speak against cross-linguistic influence, because if the German input were the reason for the relatively slow convergence to the target-like use of Italian determiners, the rate of development in Italian should not have been slower than in German, at least not in an age-based comparison. It is thus more plausible that the relatively low usage rate of Italian determiners is an effect of his overall linguistic development being slow in that language.

\section{Language-external and language-internal factors}

In the above, I formulated predictions of an account that views language dominance as the basic cause for the occurrence of cross-linguistic influence. This possibility runs counter to the empirical analysis presented here, because there were two balanced children who did show influence, and one unbalanced child who did not, which supports the conclusions drawn in earlier studies by Hulk and Müller (2000), Müller and Hulk (2001) and Müller et al. (2002).

I have further outlined the predictions of a model which postulates that the occurrence of language influence is determined by language internal reasons alone. Such a model predicts that it is always the same language that undergoes influence, namely the language that is ambiguous with respect to a structural property, one possible analysis being the "default analysis". Since DPsyntax is structurally ambiguous in both languages, this proposal cannot be used to determine the direction of influence (unless we assume that influence can take both directions, which would amount to a much weaker hypothesis) ${ }^{16}$ In order to test the $\mathrm{CH}$, I therefore followed

16 So-phrased, this weaker hypothesis would not be falsifiable. If language influence CAN occur in both directions, even the absence of language influence does not contradict the hypothesis.
Müller et al. (2002) in assuming that children prefer less complex analyses to more complex analyses and that the language with the more complex analysis is subject to influence. I have given principled reasons for the assumption that Italian provides the less complex analysis for DPs. Hence, Italian is expected to influence German. More particularly, the acquisition of German determiners should be accelerated through simultaneous exposure to Italian, independently of balance. This was borne out for the children Lukas, Carlotta and Marta. A delay in the onset of Italian articles was also observed. Although unpredicted, the delay must not necessarily count as a falsifying $\mathrm{CH}$, because it may also be a general effect of the simultaneous exposure to two languages. A more serious problem for the $\mathrm{CH}$, as already indicated by Unsworth (2003), is that it does not predict the cases in which language influence is absent. Hence, the $\mathrm{CH}$ cannot explain the case of Jan whose Italian, although it instantiates the less complex analysis for the DP-domain, does not exert any influence on German.

The solution I would like to propose is one which takes into account both language-internal factors and language balance. On the one hand, the results reported here indicate that it is irrelevant for the occurrence of cross-linguistic influence whether a child is balanced or not. On the other hand, the question arises why Jan's German cannot influence his Italian in the same way that Marta's Italian influences her German. It appears that in cases of language imbalance whether or not the stronger language influences the weaker language depends on which language is the stronger one. The present study suggests that influence in unbalanced children occurs ONLY if the stronger language is beneficial to the acquisition of the respective grammatical domain, while language influence is absent when the stronger language is not beneficial to the acquisition of that grammatical domain. ${ }^{17}$ If this conclusion is accepted, the following generalizations can be drawn:

- If bilingual children are balanced in terms of their overall linguistic development as indicated by MLU, $\mathrm{UB}$, the number of utterances and lexicon growth, there may be cross-linguistic influence with respect to grammatical phenomena showing overlap in both languages and provided that one language is more beneficial to its acquisition (i.e. less complex) than the other language.

17 An alternative explanation could be that Jan's German is not as strong (compared to monolingual children) as Marta's Italian (compared to monolingual children). This can, however, only be tested if the children's linguistic development in both languages is compared to a monolingual "norm" (cf. Müller et al. 2006). And, so far, no such norm has been established. 
- If bilingual children are unbalanced and it is the stronger language that is beneficial to the acquisition of the grammatical domain in question, this is likely to accelerate acquisition in the weaker language.

- If bilingual children are unbalanced and if the stronger language is not favorable to the acquisition of the grammatical domain in question, it cannot accelerate or slow down acquisition in the weaker language (regardless of whether or not the weaker language is favorable to the acquisition of a grammatical domain).

It is worth pointing out that the assumptions underlying these generalizations receive support from Granfeldt's (2003) and Bernardini's (2004) studies of determiner acquisition in unbalanced bilingual children. Granfeldt (2003) investigates three Swedish-French bilingual children. One of these children, Mimi, mirrors the case of Marta. Mimi is French-dominant until the age of 2;6. Although Granfeldt does not explicitly discuss the issue of language influence, he notes in passing that Mimi has an unusually low rate of determiner omission in her Swedish. He speculates that it is not implausible that her French positively influenced her Swedish: "Il n'est invraisemblable que Mimi, dont la language forte est justement le français pendant cette période, en profite pour acquérir la catégorie DP en suédois." (Granfeldt 2003, p. 108). The bilingual Swedish-French child Jean represents the opposite case and is Swedish-dominant. His rate of determiner omission in French decreases more slowly compared to Mimi's. At times, omissions are even higher in French than in Swedish, although determiners in French are known to be acquired extremely early (see e.g. Van der Velde, Jakubowicz and Rigaut, 2002). Bernardini (2004) examines a Swedish-Italian boy, Lukas, who is dominant in Swedish. Lukas acquires determiners late in Italian, although Italian generally promotes determiner acquisition. Provided that all Romance languages are similar with respect to article acquisition and all Germanic language are similar with respect to article acquisition (although being different from each other), as argued by Chierchia et al. (1999), Mimi could be a case parallel to Marta, and Jean and Lukas would be cases parallel to Jan. ${ }^{18}$

18 It should be noted that there are contradictory findings in the literature with respect to Swedish, where the definite article is a bound suffix (e.g. katt-en "cat-the") and the indefinite article a prenominal free morpheme (e.g. en katt "a cat"). Bohnacker (2004) finds that Swedish determiners appear rather early in monolingual acquisition. This would suggest, contrary to the assumptions in Chierchia (1998) and Chierchia et al. (1999), that there should be no uniform treatment of the Germanic languages. Further research will have to clarify this point.

\section{Conclusion}

This study has confirmed previous claims in the literature according to which the languages of a bilingual child may influence each other in the acquisition of grammatical domains that show structural overlap (Hulk and van der Linden, 1996; Hulk, 1997; Hulk and Müller, 2000; Müller and Hulk, 2001; Müller et al., 2002). The observational data on article use appear to falsify the hypothesis that bilingual learners have two autonomous grammatical systems. Thus, IF there WERE two grammatical systems, they are not autonomous with respect to article acquisition. One could now object that article acquisition has nothing to do with the hypothesized autonomous grammars. However, since there have been studies on the acquisition of grammatical phenomena other than articles which instantiated language influence (see above), this is not a reasonable assumption. Hence, the strongest version of the autonomy hypothesis appears to be false. Is it, then, implausible to believe in autonomous grammatical systems altogether? The answer is "no", because there are numerous empirical studies, mentioned in the beginning of this paper, which provide evidence in favor of language separation. Putting these, at first sight, contradicting pieces of information together, it seems reasonable to assume that language influence and language separation are not mutually exclusive, as argued by Gawlitzek-Maiwaldt and Tracy (1996), Hulk and Van der Linden (1996), Hulk (1997), Hulk and Müller (2000), inter alia.

The question of which factors make two language systems penetrable can only receive a tentative answer here. The comparison of the target domains has shown that the overlap with respect to determiner use in German and Italian goes beyond a structural overlap, and that the two languages also share many semantic and pragmatic conditions for article use. It is plausible that these similarities further promote the occurrence of language influence. Hence, predictions for the occurrence of language influence should not be based on syntactic criteria alone. Furthermore, it has been shown that influence was instantiated such that bilinguals are less likely than monolinguals to omit articles when these are required, but that bilinguals do not overuse articles in contexts where they must be used in Italian but not in German.

Regarding the question whether language dominance or language internal factors are decisive in determining influence, I have argued that both must be taken into account. On the one hand, as Hulk and Müller (2000) have shown, influence occurs independently of whether the children are balanced or not. On the other hand, if only language-internal factors played a role, there should have been language influence from Italian to German even in the development of children whose 
Italian constitutes the weaker language. This was not borne out. It was, therefore, proposed that influence in a particular grammatical domain only occurs if the stronger or normally developing language has language-internal properties which promote the acquisition of this domain. It does not occur, however, if the language that is beneficial to article use constitutes the weaker language.

\section{References}

Abney, S. (1987). The English noun phrase in its sentential aspect. Ph.D. dissertation, MIT.

Antelmi, D. (1997). La prima grammatica italiana. Bologna: Il Mulino.

Berman, R. (1979). The re-emergence of a bilingual: A case study of a Hebrew-English speaking child. Working Papers on Bilingualism, 19, 158-180.

Bernardini, P. (2004). L'italiano come prima e seconda (madre)lingua: Indagine longitudinale sullo sviluppo della sintassi nominale. Ph.D. dissertation, University of Lund.

Bernardini, P. \& Schlyter, S. (2004). Growing syntactic structure and code-mixing in the weaker language: The IvyHypothesis. Bilingualism: Language and Cognition, 7 (1), 49-69.

Bohnacker, U. (2004). Nominal phrases. In G. Josefsson, C. Platzack \& G. Håkansson (eds.), The acquisition of Swedish grammar, pp. 195-260. Amsterdam \& Philadelphia: John Benjamins.

Bottari, P., Cipriani, P. \& Chilosi, A. M. (1993/94). Protosyntactic devices in the acquisition of Italian free morphology. Language Acquisition, 3, 327-369.

Caselli, M. C., Leonard, L. B., Volterra, V. \& Campagnoli, M. G. (1993). Toward mastery of Italian morphology: A crosssectional study. Journal of Child Language, 20, 377-393.

Chierchia, G. (1998). Reference to kinds across languages. Natural Language Semantics, 6, 339-405.

Chierchia, G., Guasti, M. T. \& Gualmini, A. (1999). Nouns and articles in child grammar and the syntax/semantics map. Presentation given at GALA, Potsdam, Germany.

Chini, M. (1995). Genere grammaticale e acqusizione. Aspetti della morfologia nominale in italiano L2. Milano: Franco Angeli.

Cipriani, P., Pfanner, P., Chilosi, A., Cittadoni, L., Ciuti, A., Maccari, A., Pantano, N., Pfanner, L., Poli, P., Sarno, S., Bottari, P., Cappelli, G., Colombo, C. \& Veneziano, E. (1989). Protocolli diagnostici e terapeutici nello sviluppo e nella patologia del linguaggio (1/84 Italian Ministry of Health): Stella Maris Foundation.

Cordes, J. (2001). Zum unausgewogenen doppelten Erstspracherwerb eines deutsch-französisch aufwachsenden Kindes: Eine empirische Untersuchung. M.A. thesis, University of Hamburg.

De Houwer, A. (1990). The acquisition of two languages from birth: A case study. Cambridge: Cambridge University Press.

Döpke, S. (1998). Competing language structures: The acquisition of verb placement by bilingual German-English children. Journal of Child Language, 25, 555-584.
Eisenbeiss, S. (2000). The acquisition of the DP in German child language. In M. A. Friedemann \& L. Rizzi (eds.), Acquisition of syntax. Issues in comparative developmental linguistics, pp. 26-62. London: Longman.

Eisenbeiss, S. (2002). Merkmalsgesteuerter Grammatikerwerb. Eine Untersuchung zum Erwerb der Struktur und Flektion von Nominalphrasen. Ph.D. dissertation, Heinrich-HeineUniversität, Düsseldorf.

Gawlitzek-Maiwald, I. \& Tracy, R. (1996). Bilingual bootstrapping. Linguistics, 34, 901-926.

Genesee, F. (1989). Early bilingual development: One language or two? Journal of Child Language, 16, 161-179.

Genesee, F., Nicoladis, E. \& Paradis, J. (1995). Language differentiation in early bilingual development. Journal of Child Language, 22, 611-631.

Giorgi, A. \& Longobardi, G. (1991). The syntax of noun phrases. Cambridge: Cambridge University Press.

Granfeldt, J. (2003). L'acquisition des catégories fonctionnelles. Étude comparative du développement du DP fran $\varsigma$ ais chez des enfants et des adultes. Ph.D. dissertation, University of Lund.

Grosjean, F. (1982). Life with two languages. Cambridge, MA: Harvard University Press.

Guasti, M. T., De Lange, J., Gavarrò, A. \& Caprin, C. (2004). Article omission: Across child languages and across special registers. In J. Van Kampen \& S. Baauw (eds.), Proceedings of Gala 2003 (vol. 1), pp. 199-210. Utrecht: Lot Occasional Series.

Hulk, A. (1997). The acquisition of French object pronouns by a Dutch/French bilingual child. In A. Sorace, C. Heycock \& R. Shillcock (eds.), Language acquisition: Knowledge, representation, and processing. Proceedings of the GALA 1997 Conference on Language Acquisition, pp. 521-526. Edinburgh: University of Edinburgh.

Hulk, A. \& Müller, N. (2000). Crosslinguistic influence at the interface between syntax and pragmatics. Bilingualism: Language and Cognition, 3 (3), 227-244.

Hulk, A. \& Van Der Linden, E. (1996). Language mixing in a French-Dutch bilingual child. In E. Kellermann, B. Weltens \& T. Bongaerts (eds.), Eurosla 6. A selection of papers, pp. 89-101. Utrecht: Vereniging voor Toegepaste Taalwetenschap.

Jakubowicz, C. (1999). Functional categories in (ab)normal language acquisition. Presentation given at GALA, Potsdam, Germany.

Köpcke, K.-M. (1982). Untersuchungen zum Genussystem der deutschen Gegenwartssprache. Tübingen: Niemeyer.

Kupisch, T. (2000). Artikelauslassungen bei einem bilingual deutsch-italienischen Kind. M.A. thesis, University of Hamburg.

Kupisch, T. (2004). The acquisition of determiners in bilingual German-Italian and German-French children. Ph.D. dissertation, University of Hamburg.

Kupisch, T., Müller, N. \& Cantone, K. (2002). Gender in monolingual and bilingual first language acquisition: Comparing French and Italian. Lingue e Linguaggio, 1, 107-149.

Leopold, W. (1978). A child's learning of two languages. In E. Hatch (ed.), Second language acquisition, pp. 23-32. Rowley, MA: Newbury House. 
Lindholm, K. J. \& Padilla, A. M. (1978). Language mixing in bilingual children. Journal of Child Language, 5, 327-335.

Lleó, C. (2001). The interface of phonology and syntax: The emergence of the article in the early acquisition of Spanish and German. In J. Weissenborn \& B. Höhle (eds.), Approaches to bootstrapping: Phonological, lexical, syntactic and neurophysiological aspects of early language acquisition (vol. 2), pp. 23-44. Amsterdam \& Philadelphia: John Benjamins.

Lleó, C. \& Demuth, K. (1999). Prosodic constraints on the emergence of grammatical morphemes: Cross-linguistic evidence from Germanic and Romance languages. In A. Greenhill, H. Littlefield \& C. Tano (eds.), Proceedings of the 23rd Annual Boston University Conference on Child Language Development, pp. 407-418. Somerville, MA: Cascadilla Press.

Loconte, A. (2001). Zur Spachdominanz bei bilingual deutschitalienischen Kindern. M.A. thesis, University of Hamburg.

Lyons, C. (1999). Definiteness. Cambridge: Cambridge University Press.

MacWhinney, B. \& Snow, C. (1985). The Child Language Data Exchange System. Journal of Child Language, 12, 271296.

Meisel, J. M. (1986). Word order and case marking in early child language. Evidence from the simultaneous acquisition of two first languages: French and German. Linguistics, 24, $123-183$.

Meisel, J. M. (1989). Early differentiation of languages in bilingual children. In K. Hyltenstam \& L. K. Obler (eds.), Bilingualism across the lifespan: Aspects of acquisition, maturity and loss, pp. 13-40. Cambridge: Cambridge University Press.

Meisel, J. M. (1990). Two first languages: Early grammatical development in bilingual children. Dordrecht: Foris.

Meisel, J. M. (1994). Bilingual first language acquisition: French and German grammatical development. Amsterdam \& Philadelphia: John Benjamins.

Meisel, J. M. (2001). From bilingual language acquisition to theories of diachronic change. Arbeiten zur Mehrsprachigkeit, 30, 1-28.

Müller, N., Cantone, K., Kupisch, T. \& Schmitz, K. (2002). Zum Spracheneinfluss im bilingualen Erstspracherwerb: Italienisch-Deutsch. Linguistische Berichte, 190, 157-206.

Müller, N., Cantone, C., Kupisch, T. \& Schmitz, K. (2006). Einführung in die Mehrsprachigkeitsforschung. Französisch, Italienisch. (=Narr Studienbücher). Tübingen: Francke.

Müller, N. \& Hulk, A. (2001). Crosslinguistic influence in bilingual language acquisition: Italian and French as recipient languages. Bilingualism: Language and Cognition, 4, 1-21.

Müller, N. \& Kupisch, T. (2003). Zum simultanen Erwerb des Deutschen und des Französischen bei (un)ausgeglichen bilingualen Kindern. Vox Romanica, 62, 145-169.

Paradis, J., Crago, M., Genesee, F. \& Rice, M. (2003). Bilingual children with specific language impairment: How do they compare with their monolingual peers? Journal of Speech, Language and Hearing Research, 46, 1-15.
Paradis, J. \& Genesee, F. (1996). Syntactic acquisition in bilingual children: Autonomous or interdependent? Studies in Second Language Acquisition, 18, 1-15.

Penner, Z. \& Weissenborn, J. (1996). Strong continuity, parameter setting and the trigger hierarchy: On the acquisition of the DP in Bernese Swiss German and High German. In H. Clahsen (ed.), Generative perspectives on language acquisition, pp. 161-200. Amsterdam \& Philadelphia: Benjamins.

Petersen, J. (1988). Word-internal code-switching constraints in a bilingual child's grammar. Linguistics, 26, 479-493.

Pfaff, C. (1992). The issue of grammaticalization in early German second language. Studies in Second Language Acquisition, 14, 273-296.

Pizzuto, E. \& Caselli, M. C. (1992). The acquisition of Italian morphology: Implications for models of language development. Journal of Child Language, 19, 491-557.

Roeper, T. (1999). Universal bilingualism. Bilingualism: Language and Cognition, 2, 169-186.

Schlyter, S. (1993). The weaker language in bilingual SwedishFrench children. In K. Hyltenstam \& A. Viberg (eds.), Progression and regression in language: Sociocultural, neuropsychological and linguistic perspectives, pp. 289308. Cambridge: Cambridge University Press.

Schlyter, S. (1994). Early morphology in French as the weaker language in French-Swedish bilingual children. Scandinavian Working Papers in Bilingualism, 9, 67-87.

Schlyter, S. \& Håkansson, G. (1994). Word order in Swedish as the first language, second language and weaker language. Scandinavian Working Papers on Bilingualism, 9, 49-67.

Serratrice, L. (2000). The emergence of functional categories in bilingual language acquisition. Ph.D. dissertation, University of Edinburgh.

Swain, M. (1972). Bilingualism as a second language. Ph.D. dissertation, University of California at Irvine.

Szagun, G. (2001). Learning different regularities: The acquisition of noun plurals by German-speaking children. First Language, 21, 109-141.

Unsworth, S. (2003). Testing Hulk \& Müller (2000) on crosslinguistic influence: Root infinitives in a bilingual German/English child. Bilingualism: Language and Cognition, 6 (2), 143-158.

Van Der Velde, M., Jakubowicz, C. \& Rigaut, C. (2002). The acquisition of determiners and pronominal clitics by three French-speaking children. In I. Lasser (ed.), The process of language acquisition: Proceedings of the 1999 GALA Conference, pp. 115-132. Frankfurt \& Berlin: Peter Lang Verlag.

Vihman, M. M. (1985). Language differentiation by the bilingual infant. Journal of Child Language, 12, 297-324.

Volterra, V. \& Taeschner, T. (1978). The acquisition and development of language by bilingual children. Journal of Child Language, 5, 311-326.

\section{Received 28 September 2005 \\ Revision received 8 March 2006 \\ Accepted 30 March 2006}

